\title{
Computational investigation of cobalt and copper bis (oxothiolene) complexes as an alternative for olefin purification
}

\author{
Dušan N. Sredojević ${ }^{1,2}$ (D) Rajesh K. Raju ${ }^{1} \cdot$ Salvador Moncho ${ }^{1}$ - Milivoj R. Belić ${ }^{1}$ • Edward N. Brothers ${ }^{1}$
}

Received: 17 October 2019 / Accepted: 15 June 2020 / Published online: 10 July 2020

(C) The Author(s) 2020

\begin{abstract}
Considering that olefins present a large volume feedstock, it is reasonable to expect that their purification is industrially critical. After the discovery of the nickel bis (dithiolene) complex $\mathrm{Ni}\left(\mathrm{S}_{2} \mathrm{C}_{2}\left(\mathrm{CF}_{3}\right)_{2}\right)_{2}$ that exhibits electro-catalytic activity with olefins but tends to decompose by a competitive reaction route, related complexes have been explored experimentally and theoretically. In this paper, a computational examination is performed on differently charged cobalt and copper bis (oxothiolene) complexes [M $\left(\mathrm{OSC}_{2}(\mathrm{CN})_{2}\right)_{2}$ ] to test their potential applicability as the catalysts for olefin purification, using the simplest olefin, ethylene. Possible reaction pathways for ethylene addition on these complexes were explored, to determine whether some of these candidates can avoid the reaction route that leads to decomposition, which is distinctive from the nickel complex, and to form stable adducts that can subsequently release ethylene by reduction. Our calculations suggest that the neutral cobalt complex might be an alternative catalyst, because all its forms can bind ethylene to produce stable interligand adducts with moderate to low activation barriers, rather than to form intraligand adducts that lead to decomposition. The calculations also predict that these interligand adducts are capable of releasing ethylene upon reduction. In addition, it can produce the desired interligand adducts following two different reaction pathways, assigned as the direct and the indirect, with no need for anion species as co-catalysts, which is crucial for the nickel complex. Thus, the olefin purification process could be much simpler by using this catalyst.
\end{abstract}

Keywords Olefin purification $\cdot$ Density functional theory $\cdot$ Reaction mechanisms $\cdot$ Electro-catalyst

\section{Introduction}

Separation of olefins from petrochemical feedstock is an important process in the chemical industry and has attracted considerable attention for decades [1,2]. Pure olefins are necessary as precursors to produce important chemicals and polymers, but their petrochemical origin makes them appear in mixtures with several other molecules. Thus, a suitable method for their purification is required as an alternative to the

Electronic supplementary material The online version of this article (https://doi.org/10.1007/s00894-020-04445-x) contains supplementary material, which is available to authorized users.

Dušan N. Sredojević

dusan.sredojevic@qatar.tamu.edu; dusredo@vinca.rs

1 Science Program, Texas A\&M University at Qatar, Education City, Doha, Qatar

2 Institute of Nuclear Sciences, Vinča, University of Belgrade, P.O. Box 522, Belgrade 11001, Serbia currently used cryogenic distillation that is energy-intensive, and, thus, expensive [3]. Many attempts have been made to develop more cost-effective methods, such as those based on transition metal complexes [4]. However, these complexes undergo deactivation in the presence of common impurities $\left(\mathrm{H}_{2} \mathrm{O}, \mathrm{CO}, \mathrm{H}_{2} \mathrm{~S}\right.$, acetylene, etc.). A landmark in this search was the work of Wang and Stiefel in 2001, which reported an effective electrochemical system for olefin purification based on the nickel bis (dithiolene) complexes $\left(\mathrm{Ni}\left(\mathrm{S}_{2} \mathrm{C}_{2} \mathrm{R}_{2}\right)_{2}, R=\right.$ $\mathrm{CF}_{3}$ and $\mathrm{CN}$ (1) which reversibly and selectively react with the olefins and avoid poisoning by common impurities [5]. The proposed electro-catalytic reaction includes four successive steps: (I) the formation of the olefin adduct [(olefin) $\mathrm{NiL}_{2}$ ]; (II) the electrochemical reduction to produce [(olefin) $\left.\mathrm{NiL}_{2}\right]^{-}$, (III) rapid releases of the olefin to regenerate $\left[\mathrm{NiL}_{2}\right]^{-}$; (IV) the oxidation of the anionic complex $\left[\mathrm{NiL}_{2}\right]^{-}$ $\left(\mathbf{1}^{-}\right)$to the neutral species $\left[\mathrm{NiL}_{2}\right]$ (1) (Scheme 1$)$. X-ray crystallographic structural analysis has confirmed that the olefin adducts, formed in step I, possess a $\mathrm{C}-\mathrm{C}$ sequence that bridges the two sulfur atoms from the opposite dithiolene ligands, named the interligand adduct $[6,7]$. 
Scheme 1 Reaction cycle for olefin purification with nickel bis (dithiolene) complexes acting as electro-catalysts [5]

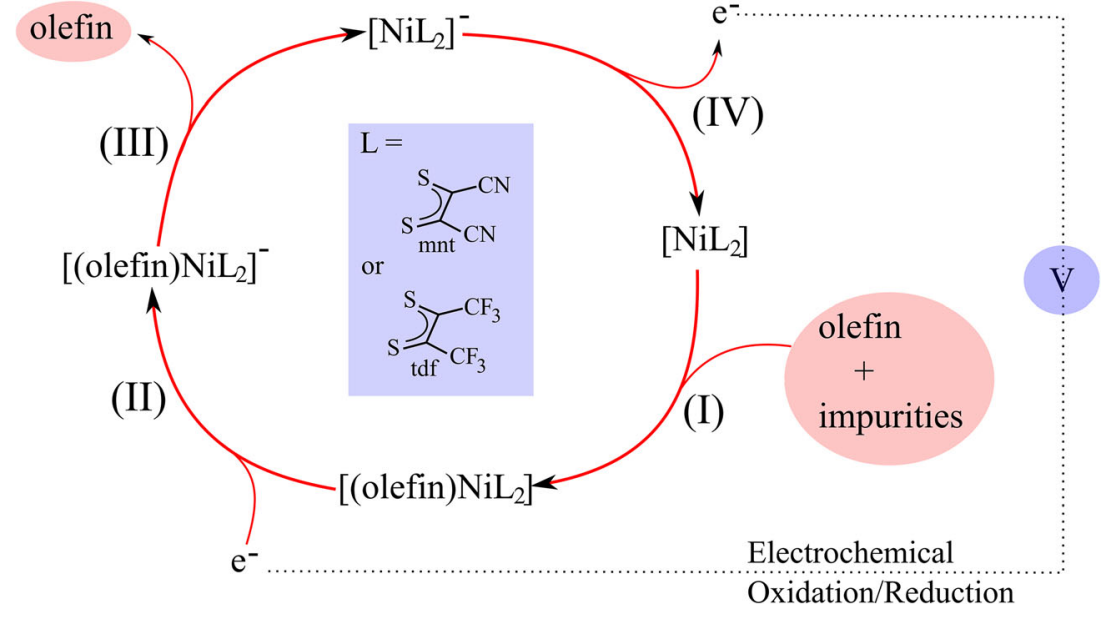

Several papers demonstrated that the metal bis (dithiolene) complexes display high reactivity toward strained and cyclic alkenes, forming cyclo-addition products [6, 8-19]. However, a direct pathway that leads to the formation of the desired cisinterligand adduct is symmetry-forbidden, which is in line with the Woodward-Hoffman addition rules [20]. Otherwise, this adduct can be formed through a twisted (pseudotetrahedral) intermediate, which is formed in the first step of the reaction, avoiding constraints imposed by orbital symmetry. This was proposed in 2002 by Fan and Hall and summarized as a two-step mechanism that begins with the olefin addition followed by isomerization [20].

Experimental results reported in 2006 suggested that the interligand adduct can only be formed in the presence of an anionic complex [ $\left.\mathrm{NiL}_{2}\right]^{-}\left(\mathbf{1}^{-}\right)$[7]. Otherwise, in the absence of the reduced complex, the main products of the reaction between $\left[\mathrm{NiL}_{2}\right]$ (1) and olefins are a series of decomposition species such as substituted dihydrodithiin (DHD) and metalcontaining products (MD). These findings led to the revision of the mechanism of 2002. The first remark was that the reaction of 1 with ethylene, in the absence of anion $\mathbf{1}^{-}$, leads to the formation of the intraligand adduct (symmetry-allowed), which further decomposes to produce experimentally detected DHD and MD species. In this isomer, the ethylene molecule forms a $\mathrm{C}-\mathrm{C}$ bridge between the two sulfur atoms on the same dithiolene ligand, forming a carbon-sulfur ring. The cisinterligand adduct can be formed via a complicated four-step process that includes different bimetallic species $\left(\mathbf{1} / \mathbf{1}^{-}\right)$and the formation of an intermediate with a Ni-S coordination of the ethylene (Scheme 2). The revised mechanism was proposed by Hall and co-workers as a result of combined experimental and theoretical studies, which highlighted the crucial role of the reduced anionic complex acting as a co-catalyst $[21,22]$.

Several theoretical studies have been published recently, with the aim of finding catalysts for olefin purification that perform better than the original nickel bis (dithiolene) complex [23-28]. In one of them, a set of novel complexes was generated by changing the nickel atom with cobalt or copper atoms and by varying the overall charge of the complex [23]. It turned out that the neutral cobalt complex $\left[\mathrm{Co}\left(\mathrm{S}_{2} \mathrm{C}_{2}\left(\mathrm{CF}_{3}\right)_{2}\right)_{2}\right]$ had the best performance for olefin purification among the tested complexes because it combined low activation barriers to form the appropriate olefin adducts without the need of a co-catalyst and to release the olefin upon reduction. Another study revealed that nickel complexes with oxothiolene ligands showed enhanced properties compared to the parent complex [24]. The two isomers of nickel bis (oxothiolene) (cis and trans) showed higher reaction selectivity toward the formation of desired interligand adducts, which are in turn much more thermodynamically stable than the intraligand adduct. Moreover, both isomers can catalyze the desired reaction with low activation barriers $(8-9 \mathrm{kcal} / \mathrm{mol})$ without the anion as a co-catalyst [22]. The most intriguing results have emerged from our previous DFT study exploring the possible reaction pathways between ethylene and nickel bis (diselenolene) complexes [25]. Surprisingly, these complexes do not decompose through intraligand adducts, because the calculated model for decomposition predicts the barriers of very high energy (38-45 kcal/mol).

In this work, we extend our previous investigations, especially those based on the cobalt and copper bis (dithiolene) and nickel bis (oxothiolene) series of complexes [23, 24]. Thus, we combined these structures to study the related cobalt and copper bis (oxothiolene) complexes (cis and trans-isomers), to examine their reactivity with ethylene. The aim is to obtain a complex that improves the performance of previous catalysts: providing low barriers, preventing the formation of the intraligand adduct (or its decomposition), and reversibly binding ethylene, while excluding the need for an anion as the co-catalyst. 
Scheme 2 The anion-catalyzed reaction competes with the intrinsic reactivity of $\mathbf{1}$ [21]

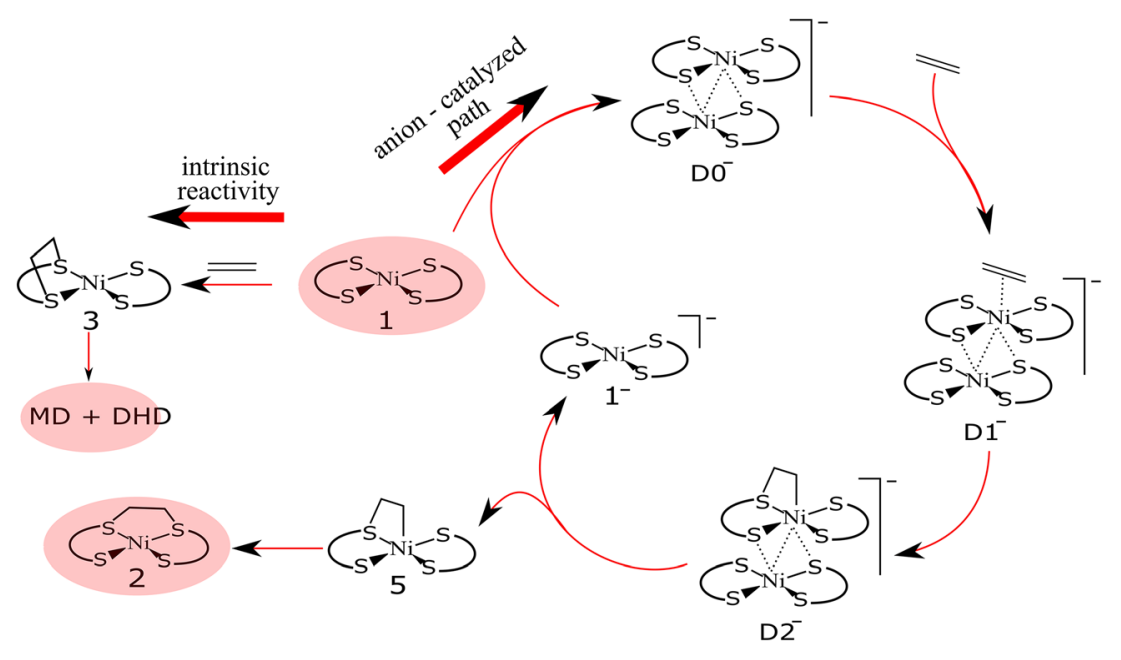

\section{Materials and methods}

All calculations have been done using the Gaussian 09 suite of programs [29]. We chose the $\omega \mathrm{B} 97 \mathrm{XD}$ [30] density functional for all calculations, because it was established that this functional produces results that are in good agreement with those obtained with the accurate coupled cluster calculations (CCSD) in a simplified model system, $\mathrm{Ni}\left(\mathrm{S}_{2} \mathrm{C}_{2} \mathrm{H}_{2}\right)_{2}$ [31]. This functional contains both long-range exchange and empirical dispersion corrections that are crucial for the accurate predictions of reaction barriers and for modeling the systems with weak interactions. The Pople all-electron $6-31++\mathrm{G}^{* *}$ basis set was specified for all atoms [32]. The geometries of all species were optimized in the gas phase and we used a vibrational analysis to determine the nature of all intermediates (no imaginary frequencies) and transition states (with only one imaginary frequency). Intrinsic reaction coordinate calculations (IRC) were applied in some cases to confirm that a transition state connects the appropriate intermediates [33]. Additional calculations were performed for all the species, to test the stability of DFT wave functions, i.e., to check that the obtained electron density corresponds to the lowest energy electron distribution $[34,35]$. For those species that we could not optimize a geometry corresponding the stable solution (very few cases), we used the equation proposed by Yamaguchi's broken-spin-symmetry procedure to estimate the energy of the spin-purified low spin state $\left({ }^{\mathrm{LS}} \mathrm{E}\right)[36,37]$. This includes the calculation of energies of the broken symmetry solution $\left({ }^{\mathrm{BS}} \mathrm{E}\right)$ and the high spin coupled state $\left({ }^{\mathrm{HS}} \mathrm{E}\right)$ in a geometry optimized using an unstable density, according to the following formula:

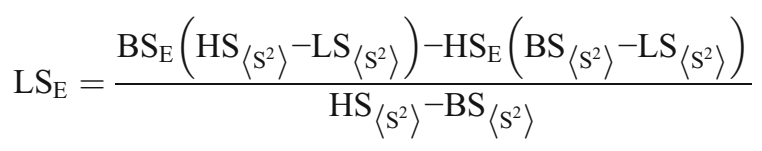

The solvation effects, with chloroform as a solvent, were calculated using the SMD method, with geometries previously optimized in the gas phase [38]. The free energies in solution ( $\Delta G_{\text {sol }}$ ) were calculated by adding solvation energies to the gas-phase relative free energies. The corrected solvent-free energy values will be used in discussion throughout the paper, unless otherwise stated. All 3D molecular structures shown in this paper were drawn using the CYLview software for molecular visualization [39].

\section{Results and discussion}

An ideal catalyst for olefin purification should prevent decomposition by imposing high energy requirements for the formation of the intraligand adduct $\mathbf{3}$, which is known for tendency to decompose. Furthermore, it should reversibly bind ethylene through a stable intermediate (such as the interligand adduct 2 or the twisted intermediate $\mathbf{2 y}$ ) with lower barriers than the previous alternatives (such as the original nickel bis (dithiolene) complex) in a pathway that does not require the anion as a co-catalyst. Keeping these demands, we followed the systematic search for alternative catalysts that were considered in our previous work. Compared to the original 1_Ni_ss complex, the two isomers of 1_Ni_os (cis/trans) [24] and 1_Co_ss [23] complexes show higher thermodynamic selectivity toward the formation of the most desired cis-interligand adduct 2 . Thus, in this paper, we examined the related [Co $\left.\left(\mathrm{OSC}_{2}(\mathrm{CN})_{2}\right)_{2}\right]^{n}(n=0,-1)$ and $\left[\mathrm{Cu}\left(\mathrm{OSC}_{2}(\mathrm{CN})_{2}\right)_{2}\right]^{n}(n=+$ $1,0,-1,-2)$ complexes and their reactions with ethylene; $\mathrm{OSC}_{2}(\mathrm{CN})_{2}$ - oxothiolene, analogous of $\mathrm{S}_{2} \mathrm{C}_{2}(\mathrm{CN})_{2}$. We start with the thermodynamic prediction of the formation of relevant adducts $(\mathbf{2}, \mathbf{2 y}$, and $\mathbf{3})$, which is briefly presented in the next section. Selected complexes from the next section with favorable thermodynamics, in accordance with above requirements, have been tested in reaction with ethylene, by locating 
the transition states (reaction barriers) to explore reaction profiles.

Thermodynamic results for the reactions of relevant complexes with ethylene Thermodynamic stability of the usual products (intra and interligand; Scheme 3 ) for different cobalt and copper bis (oxothiolene) complexes are summarized in Table 1, compared with previously reported results for nickel, cobalt and copper bis (dithiolene) [23], and nickel bis (oxothioloene) complexes [24]. The nature of the ligand is shown in the subscript after the designation of the metal, for example, 1_Ni_ss denotes nickel bis (dithiolene), while 1_Co_os denotes the cobalt bis (oxothiolene) complex. It should be noted that all bis (oxothiolene) complexes have attached $\mathrm{CN}$ groups, while bis (dithiolene) complexes are in $\mathrm{CF}_{3}$-substituted system; however, our previous studies in similar complexes suggest that both groups lead to very similar energies [21, 22, 25, 40].

Among the neutral 1_Ni_os complexes, the cis isomer exhibits more favorable thermodynamics compared to the trans isomer when ethylene is bound to the sulfur atoms. However, the coordination of ethylene in the oxygen side of the cis isomer is significantly less stable [24]. It should be noted that for the cis-isomer, O-binding ethylene adducts only exist in a twisted geometry $\mathbf{2 y}$. For the selection of the total charge of the complex, we based our selection in our previous results for bis (dithiolene) complexes. Only the neutral 1_Co_ss complex was regarded as a potential catalyst for olefin purification, while negatively charged complexes display unfavorable thermodynamics [23]. Having that in mind, we investigated only neutral and mono-anionic cobalt bis (oxothiolene) (1_Co_os ${ }^{\mathbf{0} / 1}$ -) complexes. Since previous results for 1_Cu_ss complexes showed that for positively charged and neutral complexes, the intraligand adducts 3 are more stable than inerligand adducts 2; the only alternative catalyst could be the mono-anionic 1_Cu_ss ${ }^{-}$complex, whose reaction with ethylene is predicted to be almost thermodynamically neutral. In this section, the results for the 1_Cu_os ${ }^{n}(n=+1,0,-1,-2)$ complexes are also presented. For all the copper and cobalt bis (oxothiolenes) in this study, two different spin states were considered: the lowest (singlet or doublet depending of the number of electrons) and the first higher spin state (triplet or quartet).

Cobalt bis (oxothiolene) complexes The most stable adduct for the neutral 1_Co_os complex is ${ }^{\mathbf{4}} \mathbf{2} \mathbf{y}$ (tetrahedral), in SSbinding mode, which is more stable than ${ }^{\mathbf{4}} \mathbf{2}$ (planar) by $3 \mathrm{kcal} / \mathrm{mol}$ (Table 1). In contrast, for the OS-binding mode, the cis-interligand adduct ${ }^{\mathbf{4}} \mathbf{2}$ (planar) is more stable than ${ }^{\mathbf{4}} \mathbf{2 y}$ (tetrahedral) by $2.2 \mathrm{kcal} / \mathrm{mol}$ (Table 1). As in similar complexes, the least stable adduct is the one associated with the
Scheme 3 The graphical presentation of the analyzed cobalt and copper complexes as well as their ethylene adducts. 2 , $\mathbf{2 y}$, and $\mathbf{3}$ refer to the interligand, twisted intermediate, and intraligand adducts, respectively. "**" denotes that the second binding mode is also possible (SS vs. OO)
Square-planar
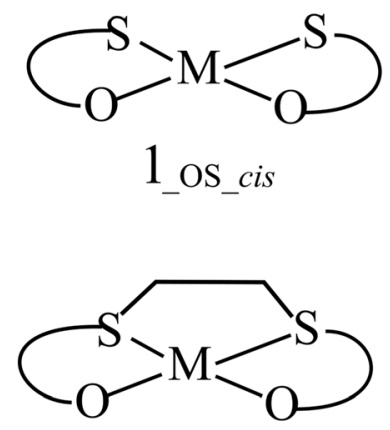

2_OS_cis_(SS)*

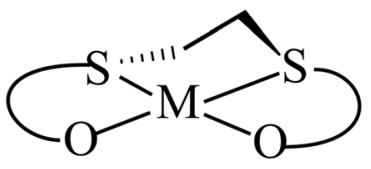

2y_os_cis_(SS)*

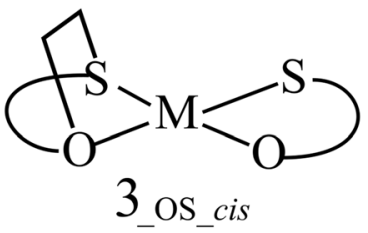

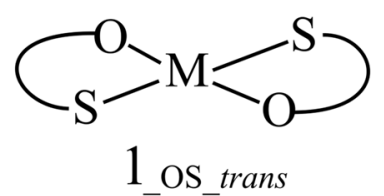<smiles>[M]O[Si]12CCOCC[SH](CCO1)C2</smiles>

2_os_trans<smiles>C1CS[Al]2C[SH](C1)OCCS2</smiles>

2y_os_trans<smiles>O=[W]1OCCS12OCCO2</smiles>

Tetrahedral<smiles>C1CS[Ge]2(O1)OCCS2</smiles>

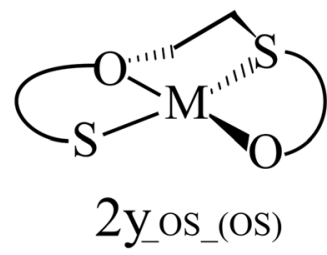

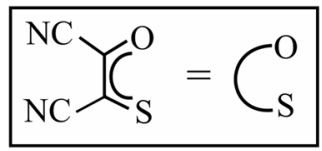<smiles>C1CS2(CCO1)CCO2</smiles> 
Table 1 Calculated free energies in solvent $\left(\mathrm{CHCl}_{3}\right)$ for the nickel, cobalt, and copper bis (dithiolene) as well as bis (oxothiolene) complexes

\begin{tabular}{|c|c|c|c|c|c|}
\hline Complex & Planar & Tetrahedral & $2 \mathrm{y}$ & 2 & 3 \\
\hline${ }^{1} 1_{-N i \_S s}[21,22]$ & 0.0 & - & -16.1 & -17.8 & -14.8 \\
\hline${ }^{1} 1_{\text {Ni__OS_cis }}[24]$ & 0.0 & - & -8.6 & -19.1 & 3.9 \\
\hline${ }^{1} 1_{\text {_Ni_OS_trans }}[24]$ & 0.0 & - & - & -7.5 & 5.2 \\
\hline${ }^{2} 1$ Co_SS [23] & 0.0 & - & -22.3 & -25.6 & -13.3 \\
\hline${ }^{4} 1_{\mathrm{Co} O S}$ & - & 0.0 & $\begin{array}{l}-\underline{\mathbf{2 7 . 2}} \frac{(\mathrm{SS})}{8.1_{(\mathrm{OO})}} \\
-18.2(\mathrm{OS})\end{array}$ & $\begin{array}{l}-24.2(\mathrm{SS}) \\
-20.4(\mathrm{OS})\end{array}$ & $-10.5^{\mathrm{a}}$ \\
\hline${ }^{2} 1$ Co_OS_cis & 6.3 & - & $\begin{array}{l}0.3(\mathrm{OS}) \\
2.9(\mathrm{OO})\end{array}$ & -13.5 (SS) & 12.2 \\
\hline${ }^{2} 1_{\text {Co_OS_trans }}$ & 4.6 & - & $-14.6_{(\mathrm{SS})}$ & $-2.1(\mathrm{OS})$ & 13.8 \\
\hline${ }^{1} 1_{-}$Co_OS_cis ${ }^{-}$ & 6.6 & - & $\begin{array}{l}22.1_{(\mathrm{SS})} \\
43.0(\mathrm{OO})\end{array}$ & 25.7 & $44.1^{\mathrm{a}}$ \\
\hline${ }^{1} 1_{\text {Co_OS trans }}{ }^{-}$ & 8.5 & - & 32.2 & 32.8 & $44.1^{\mathrm{a}}$ \\
\hline${ }^{3} 1_{-}$Co_OS - & - & 0.0 & $\begin{array}{l}7.1_{(\mathrm{SS})} \\
26.7(\mathrm{OO})\end{array}$ & 12.3 & 41.2 \\
\hline${ }^{1} 1_{\_} \mathrm{Cu}_{-} \mathrm{Ss}^{-}{ }^{-}[23]$ & 0.0 & - & -9.5 & -3.3 & -1.5 \\
\hline${ }^{1} 1_{-} \mathrm{Cu}_{-} \mathrm{OS}{ }^{+}$ & - & 0.0 & $\begin{array}{l}-17.5_{(\mathrm{SS})} \\
-22.2_{(\mathrm{OO})}\end{array}$ & -17.9 & $-32.0^{\mathrm{a}}$ \\
\hline${ }^{3} 1_{-} \mathrm{Cu} \_\mathrm{OS} \_$cis ${ }^{+}$ & 3.1 & - & $\begin{array}{l}-21.4_{(\mathrm{SS})} \\
-\mathbf{2 5 . 6}(\mathrm{OO})\end{array}$ & -20.4 & -24.5 \\
\hline${ }^{3} 1_{1}$ Cu_OS_trans ${ }^{+}$ & 3.4 & - & -21.6 & -23.3 & $-23.0^{\mathrm{a}}$ \\
\hline${ }^{2} 1_{-} \mathrm{Cu} \_\mathrm{OS} \_c i s$ & 0.4 & - & $\begin{array}{l}-15.2_{(\mathrm{SS})} \\
-7.0(\mathrm{OO})\end{array}$ & -20.1 & $-20.4^{\mathrm{a}}$ \\
\hline${ }^{4}{ }_{-}$Cu_OS_cis & 0.0 & - & $\begin{array}{l}32.9_{(\mathrm{SS})} \\
33.3_{(\mathrm{OO})}\end{array}$ & 29.9 & $19.8^{\mathrm{a}}$ \\
\hline${ }^{2} 1_{\text {CCu_OS_trans }}$ & 0.5 & - & -13.2 & -13.5 & $-20.9^{\mathrm{a}}$ \\
\hline${ }^{4} 1$ _Cu_OS_trans & 0.0 & - & 37.2 & 27.5 & 19.1 \\
\hline$\frac{{ }^{1} 1_{\mathrm{Cu} \text { OS } c i s}}{}$ & 0.8 & 0.8 & $-\frac{17.4_{(\mathrm{SS})}}{5.9_{(\mathrm{OO})}}$ & -13.4 & $0.1^{\mathrm{a}}$ \\
\hline${ }^{3} 1_{-} \mathrm{Cu}_{-} \mathrm{OS}{ }^{-}$ & - & 0.0 & $\begin{array}{l}25.4_{(\mathrm{SS})} \\
27.8_{(\mathrm{OO})}\end{array}$ & 35.5 & 33.5 \\
\hline${ }^{2} 1_{-} \mathrm{Cu}_{-} \mathrm{OS}^{2-}$ & - & 0.0 & 39.2 & 44.2 & $36.8^{\mathrm{a}}$ \\
\hline${ }^{4} 1_{-} \mathrm{Cu}_{-} \mathrm{OS}^{2-}$ & - & 55.7 & 82.0 & 85.7 & $79.3^{\mathrm{a}}$ \\
\hline
\end{tabular}

Denotations inside the parenthesis (SS, OS, and OO) indicate that ethylene binds to the sulfur atoms, oxygen and sulfur, and oxygen atoms of different chelates, respectively

${ }^{a}$ Broken geometry with three atoms coordinated to the metal atom

OO-binding mode, which can only exist in twisted geometry ${ }^{4} \mathbf{2 y}(-8.1 \mathrm{kcal} / \mathrm{mol})$. Nevertheless, the ${ }^{\mathbf{4}} \mathbf{2}$ Co_os adducts in SS and OS binding modes are more stable than adduct ${ }^{\mathbf{4}} \mathbf{3}_{\text {_Co_os, }}$ by 13.7 and $9.9 \mathrm{kcal} / \mathrm{mol}$, respectively. That difference is much larger than for the $\mathbf{1}_{\mathbf{N i} \text { ss }}$ system, and comparable for those in the 1 Co $\mathbf{s}$ ss system, suggesting a higher selectivity toward the formation of desired interligand products. In the doublet state, the ${ }^{2}$ 1_Co_os_cis complex, in SS-binding mode, shows the biggest difference between relative stability of adducts 2 and $\mathbf{3}, 25.7 \mathrm{kcal} / \mathrm{mol}$, larger than for its nickel analog 11_Ni_os_cis $(23 \mathrm{kcal} / \mathrm{mol})$ [24]. For the trans-isomer $\left({ }^{2} 1_{-}\right.$Co_os_trans $)$, the difference is moderate $(15.9 \mathrm{kcal} / \mathrm{mol})$ and the ${ }^{2}$ _Co_os_trans adduct is not quite stable $(-2.1 \mathrm{kcal} /$ mol). Nevertheless, it can be concluded that, from thermodynamic values, the neutral 1 Co os complex, in both spin states, might be regarded as an alternative catalyst (Table 1; underlined). The anionic cobalt complex (1_Co_os_cis $\left.{ }^{-}\right)$, which is isoelectronic to the neutral $\mathbf{1}_{\mathbf{N i} \text { NSs }}$ and $\mathbf{1}_{\mathbf{N i} \_\mathbf{O S}}$, favors the triplet state, as well as its ethylene adducts. However, ethylene adducts on anionic cobalt are thermodynamically unfavorable, which might be excluded as candidates for the olefin separation process. The reason for this can be attributed to the fact that ethylene plays a role of nucleophile in these reactions. On the other hand, the instability of anionic adducts, in both spin states, supports the claim of the neutral cobalt complex, because the ethylene could be released from these adducts after reduction.

Copper bis (oxothiolene) complexes Among the copper complexes, only the mono-anionic complex ( ${ }^{\mathbf{1}} \mathbf{1}$ Cu_os $\left.{ }^{-}\right)$might be regarded as an alternative catalyst according to our two main requirements (Table 1; underlined). First, due to the favorable 
thermodynamics of both interligand adducts $\left({ }^{1} \mathbf{2} \mathbf{y}_{-} \mathbf{C u}_{0} \mathbf{O S}_{\text {_cis }}{ }^{-}\right.$, ${ }^{12}$ Cu_Os_cis ${ }^{-}$by 17.4 and $13.4 \mathrm{kcal} / \mathrm{mol}$, respectively) compared to the intraligand ${ }^{1} \mathbf{3}_{\text {_Cu_os_cis }}{ }^{-}$(isoenergetic with the reactants). Second, because their adducts become unstable upon reduction, 2 y $\mathbf{C u}$ os cis $^{2-}, 2$ Cu os ${ }^{2}{ }^{2-}$, $3_{\text {Cu_os_broken }}{ }^{2-}$ are at least $35 \mathrm{kcal} / \mathrm{mol}$ less stable than the ethylene release products). Despite the mono-anionic copper complex 1_Cu_os ${ }^{-}$prefers triplet state, this spin state shows very unfavorable thermodynamics for the ethylene bindings.

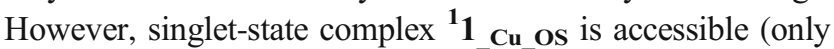
slightly less stable than the triplet $\sim 0.8 \mathrm{kcal} / \mathrm{mol}$ ) and can adopt both planar (only as the cis-isomer) and tetrahedral geometries. On the other hand, cationic and neutral complexes can be discarded because the stability of intraligand, decomposing adducts (like the interligand or significantly more stable). On the other hand, the double-anionic complex 1_Cu_os ${ }^{2-}$ has very unfavorable thermodynamics for ethylene binding in both spin states, probably because it is too electronrich to act as an electrophile. This makes it not feasible as a catalyst, but contributes to the feasibility of the monoanionic complex, because their adducts can be released upon reduction.

The relative stability of adducts The stability of ethylene adducts with the series of isoelectronic species decreases from that with cationic copper $\left(\mathbf{1}_{-} \mathrm{Cu}_{\text {OOS_cis/trans }}{ }^{+}\right)$, through neutral nickel (1_Ni_os_cis/trans) $)$ [24], to anionic cobalt (1_Co_os_cis/ trans $^{-}$) complexes (see Table 1). There are two explanations for this trend. First, considering that the ethylene acts as a nucleophile in these reactions, it is reasonable that its addition to the positively charged copper complex is more favorable than to the neutral nickel complex, which is in turn, more favorable than to the negatively charged cobalt complex. The second explanation can be given through the analysis of the frontier molecular orbitals (FMO) of relevant species. Thus, we compared the energy differences $(\Delta \mathrm{E})$ between LUMO orbitals of different cis-isomers, which appear to be similar for all three complexes, and HOMO orbital of ethylene (Table 2). It is evident from Table 2 that $\Delta E$ increases in the following order: 1_Cu_Os_cis ${ }^{+}<\mathbf{1}$ _Ni_Os_cis $<$ 1_Co_Os_cis ${ }^{-}$, thereby reducing the binding abilities of certain complex to ethylene (Table 2). In respect to the series of isocharged complexes $\left({ }^{1}{ }_{1}\right.$ Ni_Os_cis,${ }^{2}$ 1_Co_OS_cis, ${ }^{2}$ 1_Cu_os_cis $), \Delta E$ values are similar in all three cases. The higher deviation in stability is noticed for adduct ${ }^{2} \mathbf{3}_{\mathrm{Cu}}$ os, which has three-coordinated broken geometry.

Reaction mechanisms for cobalt bis (oxothiolene) complexes with ethylene According to the thermodynamic results in Table 1, the neutral species $\left({ }^{\mathbf{2}} \mathbf{1}\right.$ Co_os_cis, ${ }^{\mathbf{2}} \mathbf{1}_{\mathbf{C}} \mathbf{C o}$ os_trans, and ${ }^{4} 1_{C}$ Co_os) display promising properties for ethylene binding and might be regarded as a potential catalyst. Thus, the reaction mechanisms were investigated, by locating all possible
Table 2 Energies (eV) of frontier orbitals (FMO) for different complexes and ethylene

\begin{tabular}{|c|c|c|c|}
\hline Complex & HOMO & LUMO & $\Delta E^{\mathrm{a}}$ \\
\hline $\mathrm{C}_{2} \mathrm{H}_{4}$ & -9.50 & 2.58 & \\
\hline${ }^{1} 1$ _Ni_OS_cis & -8.35 & -4.17 & 5.33 \\
\hline${ }^{2} 1$ _Co_OS_cis & $-8.88(-8.89)$ & $-3.28(-3.18)$ & $6.22(6.32)$ \\
\hline${ }^{1} 1$ Co_os_cis ${ }^{-}$ & -7.39 & -1.35 & 8.15 \\
\hline${ }^{3} 1_{\text {CCu_OS_cis }}{ }^{+}$ & $-9.99(-11.55)$ & $-5.45(-5.46)$ & $4.05(4.04)$ \\
\hline${ }^{2} 1$ _Cu_OS_cis & $-8.74(-9.56)$ & $-1.88(-3.53)$ & $7.62(5.97)$ \\
\hline
\end{tabular}

All complexes in this table have planar geometries. For ${ }^{2} \mathbf{1}_{\text {Co_os }}$ cis,${ }^{3} \mathbf{1}$ Cu_os_cis ${ }^{+}$, and ${ }^{2} 1_{C}$ Cu_os_cis complexes, values inside the parentheses correspond to the $\bar{\beta} \mathrm{MO}$, whereas those outside the parentheses correspond to the $\alpha \mathrm{MO}$

${ }^{\text {a }} \Delta E$ represents energy difference between complex's LUMO and ethylene's HOMO. Energies are given in $\mathrm{eV}$ and represent solvent-corrected MO energies that were calculated at $\omega$ B97X-D/6-31G(d,p) level. Smaller basis set was chosen to produce valence-like LUMOs

intermediates and transition states, to estimate its potential from a kinetic point of view. Based on our previous research, two main types of mechanisms have been explored for neutral cobalt bis (oxothiolene) complexes. In the first mechanism, referred to as the "direct" pathway, ethylene adds directly to the sulfur (oxygen) of the same or opposite ligands, forming intraligand and interligand adducts, respectively. The second mechanism, referred as "indirect", is characterized by the formation of an intermediate in the first step of the reaction, in which ethylene is bound to metal and ligator atoms. This intermediate can further transform into both interligand and intraligand adducts. In this section, both reaction pathways for all 1_Co_os species (in both spin states) are reported. Furthermore, for each pathway, two possible approaches of ethylene were considered, depending if the initial coordination of the ethylene molecule is on sulfur or oxygen atoms (referred as S- and O-binding side). In general, the O-bindingside pathways are higher in energy and not competitive with the S-binding-side alternatives; for this reason, they are not detailed here and reported as Supporting Information. Although ${ }^{\mathbf{4}} \mathbf{1}_{\text {Co os }}$ is tetrahedral (with no cis/trans isomerism), its reactivity is also described in two parts, divided into cis and trans based on the square-planar intermediates and products.

Coupled-cluster calculations The results for the neutral cobalt bis (oxothiolene) complexes show that the quartet-state ${ }^{4} 1_{\text {Co os }}$ (tetrahedral) complex is more stable than the double-state complexes ${ }^{2} \mathbf{1}$ _Co_os _cis and ${ }^{2} \mathbf{1}$ _Co_os_trans (planar) by 6.3 and $4.6 \mathrm{kcal} / \mathrm{mol}$, respectively (Table 1 ). However, it has been proven that $\omega$ B97X-D functional can overestimate the energy gap between high- (HS) and low-spin (LS) states, in favor of the high spin state [23]. In order to check this and improve our estimation of the energy difference 
between complex in high $\left({ }^{\mathbf{4}} \mathbf{1}_{\text {_Co_os }}\right)$ and low $\left({ }^{\mathbf{2}} \mathbf{1}_{\text {_Co_os_cis/ }}\right.$ trans) spin state, high-level calculations were done using $\operatorname{CCSD}(\mathrm{T})$ with the same basis set $(6-31++\mathrm{G}(\mathrm{d}, \mathrm{p}))$ in a simplified model of general formula $\mathrm{Co}\left(\mathrm{OSC}_{2} \mathrm{H}_{2}\right)_{2}$ (1 $\left.\mathbf{1}_{\text {Co_model }}\right)$. These calculations show that ${ }^{2} \mathbf{1}_{\text {Co model cis }}$ (planar) is more stable than ${ }^{4} \mathbf{1}_{\text {Co model }}$ (tetrahedral) by $2.1 \mathrm{kcal} / \mathrm{mol}$ (electronic energy), which is, in turn, more stable than ${ }^{\mathbf{2}} \mathbf{1}_{\text {_Co_model_trans }}$ (planar) by $2.8 \mathrm{kcal} / \mathrm{mol}$ (electronic energy). In contrast, according to the $\omega \mathrm{B} 97 \mathrm{X}-\mathrm{D}$ calculations, the most stable species is ${ }^{4} \mathbf{1}_{\text {Co model }}$ (tetrahedral), which is more stable than ${ }^{2} 1$ _Co_model_cis and ${ }^{2} 1_{\text {_CC_model_trans }}$ (planar) by 5.0 and $8.2 \mathrm{kcal} / \mathrm{mol}$ (electronic energy), respectively. Hence, $\omega$ B97X-D functional overestimates the high spin by at least $7 \mathrm{kcal} / \mathrm{mol}$ for 1_Co_model comparing to the $\operatorname{CCSD}(\mathrm{T})$. However, $\operatorname{CCSD}(\mathrm{T})$ calculations in the ethylene adducts show that ${ }^{\mathbf{4}}$ 2_Co_model_cis is more stable than ${ }^{2}$ 2_Co_model_cis by $14.1 \mathrm{kcal} / \mathrm{mol}$ (electronic energy). The differences in stability between two spin states for various interligand adducts, according to the $\omega \mathrm{B} 97 \mathrm{X}-\mathrm{D}$ functional, are in range from 11 to $18 \mathrm{kcal} / \mathrm{mol}$, in favor of high-spin state. This indicates that $\omega \mathrm{B} 97 \mathrm{X}-\mathrm{D}$ functional gives accurate prediction for the relative stability of the spin states in the interligand adducts (in comparison with the reactant complex). Hence, we consider that both spin states are similar in energy and both are accessible, and we will study the mechanism of the reaction in both spin states. Additional details on the $\operatorname{CCSD}(\mathrm{T})$ calculations can be found in the Electronic Supplementary Material (Fig. S1/S2 and Tables $\mathrm{S} 1 / \mathrm{S} 2$ ).

Energy profile of 1_co_os for quartet spin state The quartetstate energy surface of ${ }^{4} \mathbf{1}_{\text {Co_os }}$ and ethylene is presented in Fig. 1 (dotted red and solid black lines assign direct and indirect pathways, respectively). The optimized geometries of significant intermediates and transition states are presented in Fig. 2. In the cis-reaction profile, the direct pathway lead to a twisted, interligand product ${ }^{4} \mathbf{2} \mathbf{y}_{\text {os }}$ (tetrahedral) with an ac-

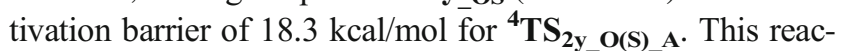
tion follows a stepwise pathway including the intermediate ${ }^{4} \mathbf{2} \mathbf{y}_{-} \mathbf{O}(\mathbf{S})$ Int (biradical species with one electron of $\beta$ spin excess located on $\mathrm{C}_{2}$ carbon atom: Fig. 2). Formation of the intraligand adduct ${ }^{\mathbf{4}} \mathbf{3}_{\text {_os }}$ via direct pathway was not located neither in a direct step nor successively. Along the indirect pathway for the cis-reaction profile, the intermediate ${ }^{4} 5_{-}$o(S)_cis, in which ethylene is connected to the Co and $\mathrm{S}$ atoms, can be formed via transition state ${ }^{\mathbf{4}} \mathbf{T S} \mathbf{S}_{\mathbf{1 5} \_ \text {O(S)_cis }}$ by crossing the barrier of $14.7 \mathrm{kcal} / \mathrm{mol}$. This intermediate can further isomerize into different both interligand (planar ${ }^{4} \mathbf{2}_{\mathbf{O}} \mathbf{O}(\mathrm{S}) \_$cis and tetrahedral ${ }^{\mathbf{4}} \mathbf{2} \mathbf{y}_{-} \mathbf{o s}$ ) and intraligand $\left({ }^{4} \mathbf{3}_{-}^{-}\right.$os broken $)$adducts, by overcoming barriers of $4.3 \mathrm{kcal} /$ $\mathrm{mol}\left({ }^{\mathbf{4}} \mathbf{T S}_{\mathbf{5 2} \_} \mathbf{O}(\mathbf{S}) \_c i s\right), 15.6 \mathrm{kcal} / \mathrm{mol}\left({ }^{\mathbf{4}} \mathbf{T S}_{52 \mathbf{y}} \mathbf{O}(\mathbf{S}) \_c i s\right)$, and $\left.20.7 \mathrm{kcal} / \mathrm{mol}^{\mathbf{4}}{ }^{\mathbf{T} \mathbf{T S}_{\mathbf{5 3}} \mathbf{O}(\mathbf{S}) \text { cis }}\right)$, respectively. There is a high kinetic selectivity $(16.4 \mathrm{kcal} / \mathrm{mol}$ compared with the intraligand isomer) towards the formation of desired interligand adduct ${ }^{\mathbf{4}} \mathbf{2}$ o(s) cis. The indirect pathway that leads to ${ }^{4} \mathbf{2}_{\mathbf{O}} \mathbf{O}(\mathbf{S})_{\text {ccis }}$ is kinetically and thermodynamically most favorable, with a rate-determining barrier of $14.7 \mathrm{kcal} / \mathrm{mol}$.

About the trans-reaction profile (Fig. 1, left side), the direct pathway forms the twisted interligand adduct ${ }^{\mathbf{4}} \mathbf{2} \mathbf{y}_{-} \mathbf{o}(\mathbf{s})$ (tetrahedral) with an activation barrier of $18.9 \mathrm{kcal} / \mathrm{mol}$

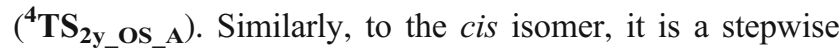
process with the formation of the first $\mathrm{C}-\mathrm{S}$ bond leading to the intermediate ${ }^{\mathbf{4}} \mathbf{2} \mathbf{y}_{-} \mathbf{o s} \_$Int. This intermediate can further

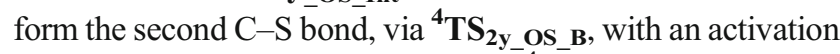
barrier of only $0.6 \mathrm{kcal} / \mathrm{mol}$ relative to $\mathbf{4} \mathbf{2} \mathbf{y}_{-}$os_Int. Like the cisreaction profile, the hypothetic formation of the intraligand adduct ${ }^{4} \mathbf{3}_{\text {_os_broken }}$ through direct pathway was not located neither directly nor successively. The alternative indirect pathway includes the formation of an intermediate ${ }^{\mathbf{4}} \mathbf{5}$ o(S)_trans (the ethylene is connected to the Co and $\mathrm{S}$ atoms) with an activation barrier of $13.8 \mathrm{kcal} / \mathrm{mol}\left({ }^{\mathbf{4}} \mathbf{T S}_{\mathbf{1 5}} \mathbf{O}\right.$ (S)_trans) ). ${ }_{5}^{5}$ o(S) trans can isomerize into three different adducts both interligand $\left({ }^{\mathbf{4}} \mathbf{2}\right.$ os_trans and $\left.{ }^{\mathbf{4}} \mathbf{2} \mathbf{y} \_\mathbf{o ( s )}\right)$ and intraligand ( ${ }^{4}$ _os_broken, which can lead to the decomposition). However, the transition states that lead to the formation of interligand adducts $\left({ }^{\mathbf{4}} \mathbf{2}\right.$ os_trans and $\left.{ }^{\mathbf{4}} \mathbf{2} \mathbf{y}_{-} \mathbf{o ( s )}\right)$ are 8.3 and $13.1 \mathrm{kcal} / \mathrm{mol}$ lower in energy than one associated with the formation of the intraligand adduct, respectively. This indicates that indirect pathway drives the reaction toward the formation of the desired interligand adducts $\left({ }^{4} \mathbf{2}_{-} \mathbf{O} \mathbf{S}_{-}\right.$trans and ${ }^{4} \mathbf{2 y}_{\mathbf{O}} \mathbf{O ( S )}$ ) over the formation of broken adduct ${ }^{\mathbf{4}} \mathbf{3}_{\text {_os_broken }}$, both kinetically and thermodynamically.

The reactivity starting by an oxygen atom (O-binding side) for both cis-and trans-reaction profile is clearly less favorable and not competitive with the results above (Electronic Supplementary Material; Fig. S4). For the cis-reaction profile activation, barriers amount 30.0 and $27.8 \mathrm{kcal} / \mathrm{mol}$ for the direct and indirect pathways, respectively. For the trans-reaction profile, we were unable to obtain appropriate intermediates or transition states for the direct mechanism and the indirect mechanism has a barrier of $28.2 \mathrm{kcal} / \mathrm{mol}$.

Totally, the reaction between ${ }^{\mathbf{4}} \mathbf{1}$ _Co_os and ethylene prefers the formation of interligand adducts with respect to the intraligand adduct, both thermodynamically and kinetically, thereby minimizing the decomposition route.

Energy profile of 1 co_os for doublet spin state On the other hand, doublet state energy profile for the reaction between ${ }^{2} 1$ Co_os (cis/trans) and ethylene is presented in Fig. 3 (optimized geometries of selected species in Fig. 4). This energy profile shows the direct (dotted lines) and indirect (solid lines) pathways that can act along the S-binding side (the energy profile for O-binding side is presented in Electronic Supplementary Material; Fig. S5). The cis-isomer is converted, through the direct mechanism, to generate ${ }^{\mathbf{2}} \mathbf{2 y}$ so (tetrahedral) in a stepwise mechanism involving the formation of intermediate ${ }^{2} \mathbf{2} \mathbf{y}_{-} \mathbf{o}(\mathbf{S}) \_$Int (with only one C-S bond a 


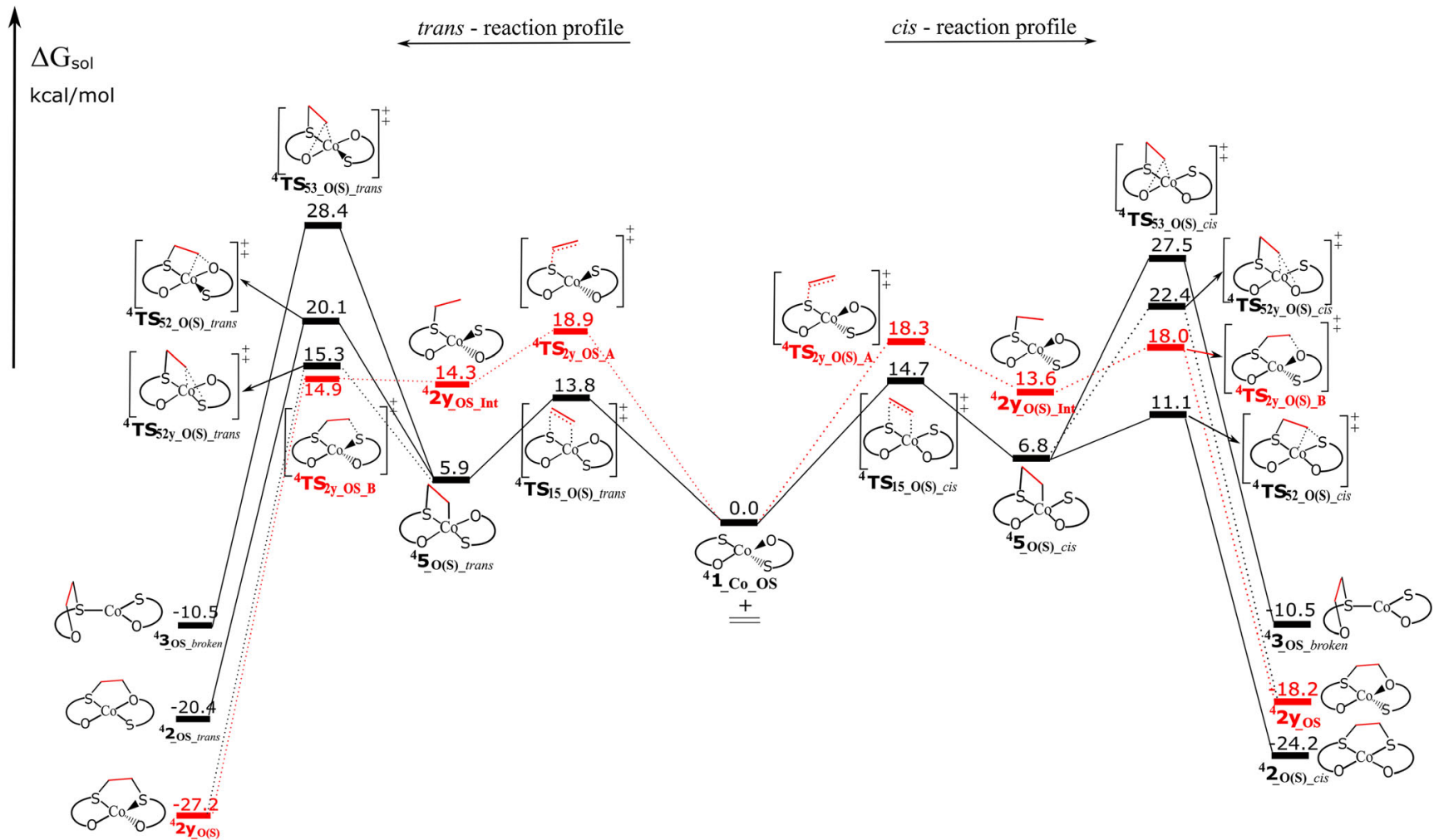

Fig. 1 Calculated energy surfaces for the reaction of ${ }^{\mathbf{4}} \mathbf{1}$ Co_os with ethylene, for the cis-and trans-reaction profiles, considering S-binding side. Dotted (red) lines represent direct and solid (black) lines represent indirect pathway. Energies in $\mathrm{kcal} / \mathrm{mol}$ are the free energies in solvent $\left(\mathrm{CHCl}_{3}\right)$
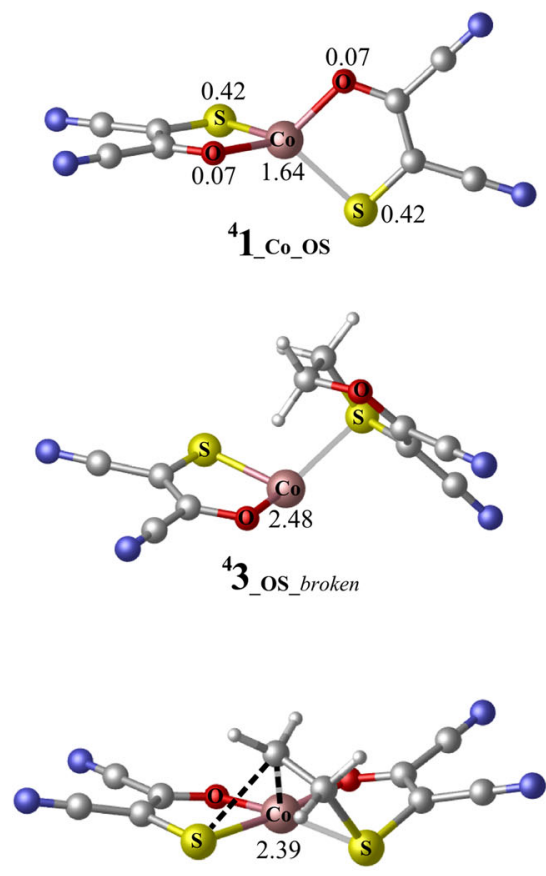

${ }^{4} \mathbf{T S}_{\mathbf{5 2}_{2} \mathbf{O}(\mathrm{S}) \_ \text {cis }}$
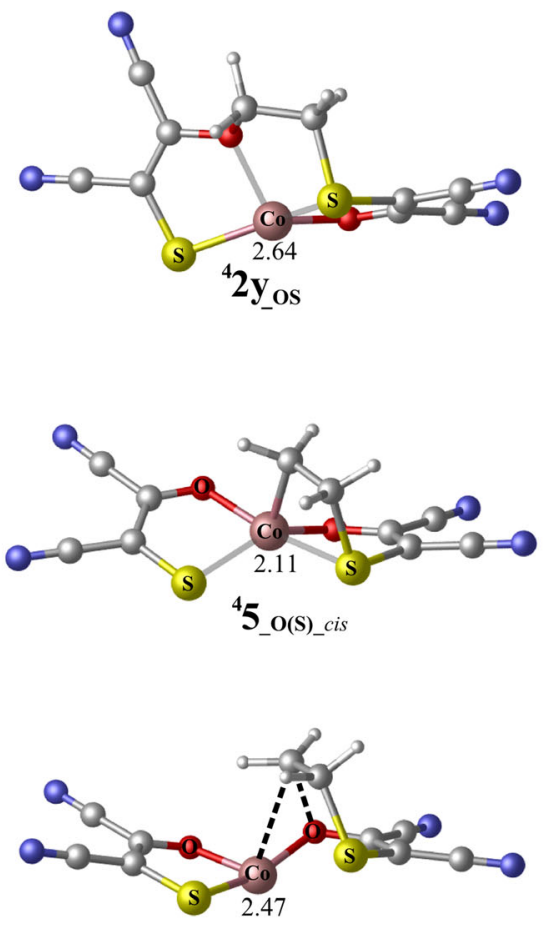

${ }^{4} \mathbf{T S}_{53 \_} \mathbf{O}(\mathbf{S})_{-}$is
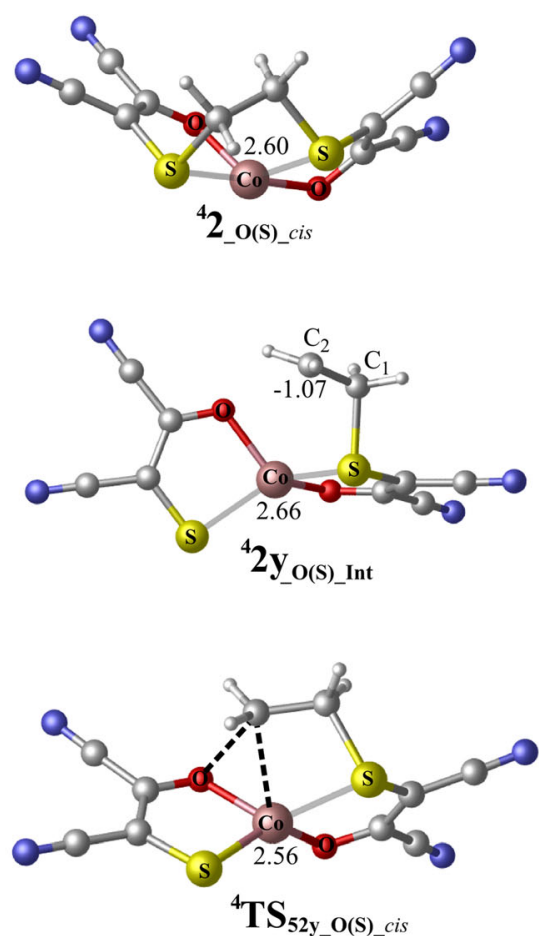

Fig. 2 The optimized geometries for the selected species of $c i s$-reaction profile that are included in Fig. 1. Values correspond to atomic spin densities. The geometries of selected species for trans-reaction profiles are presented in Electronic Supplementary Material (Fig. S3) 


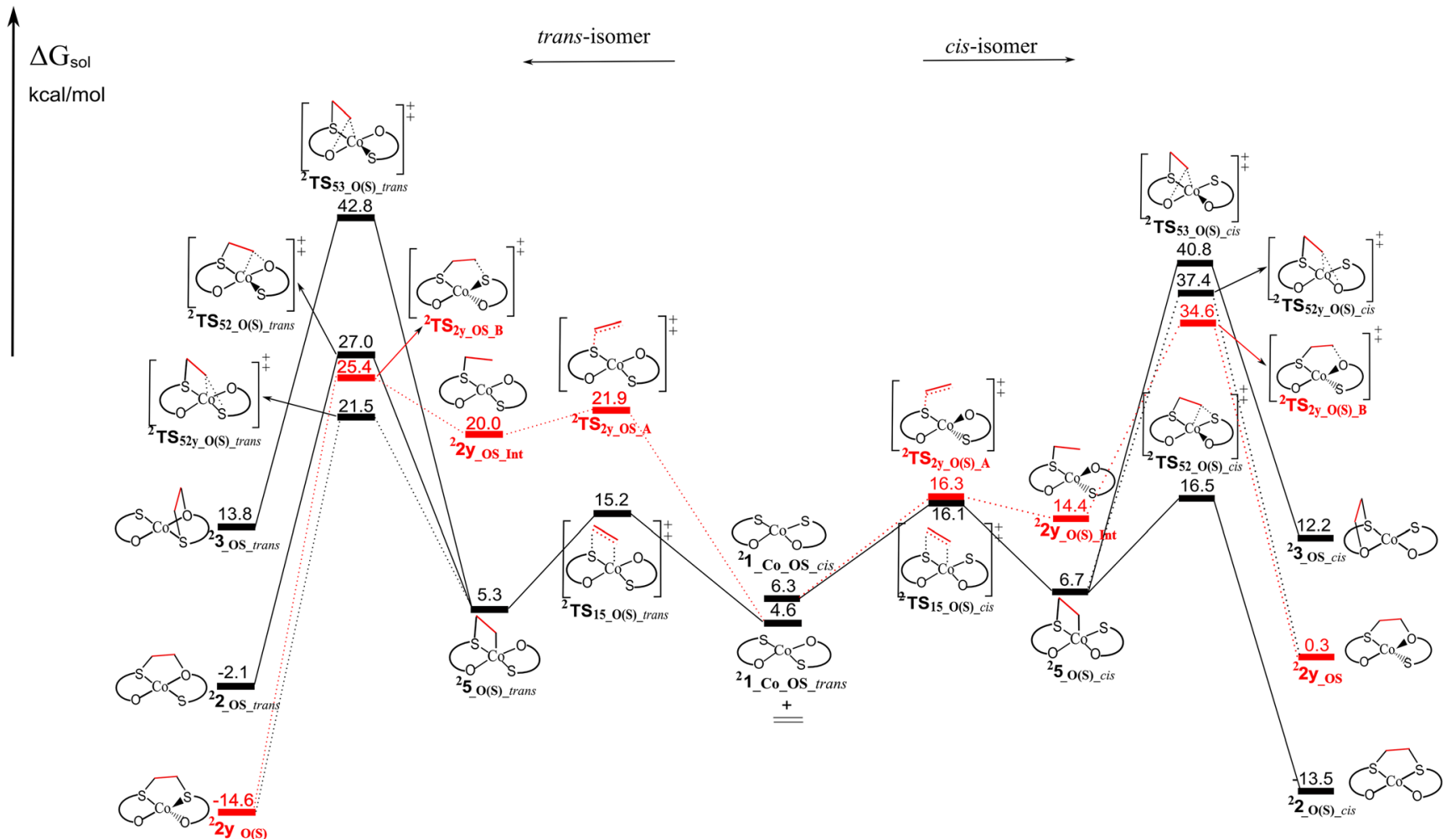

Fig. 3 Calculated energy surfaces for the reaction of ${ }^{\mathbf{2}} \mathbf{1}$ _co_os $($ cis/trans) with ethylene, along the S-binding side. Dotted (red) and solid (black) represent direct and indirect, respectively. Energies in $\mathrm{kcal} / \mathrm{mol}$ are the free energy in solvent $\left(\mathrm{CHCl}_{3}\right)$
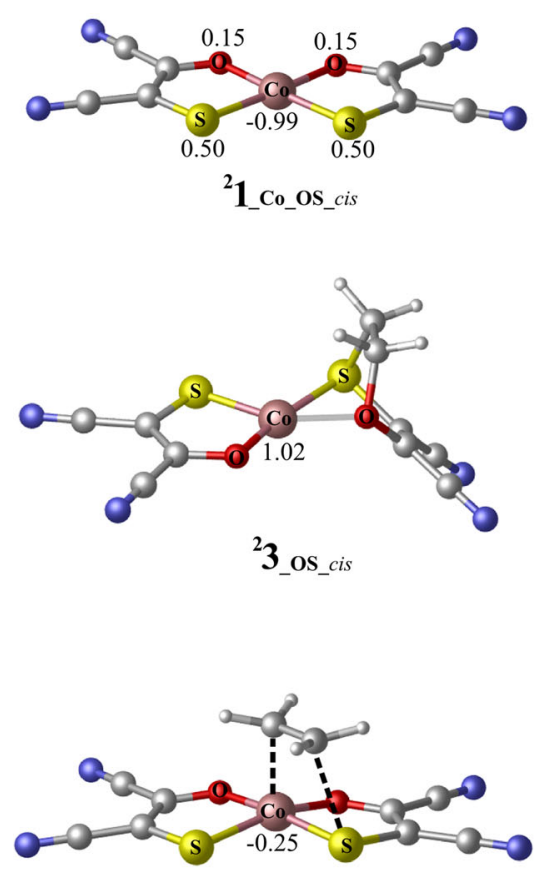

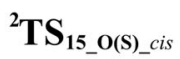
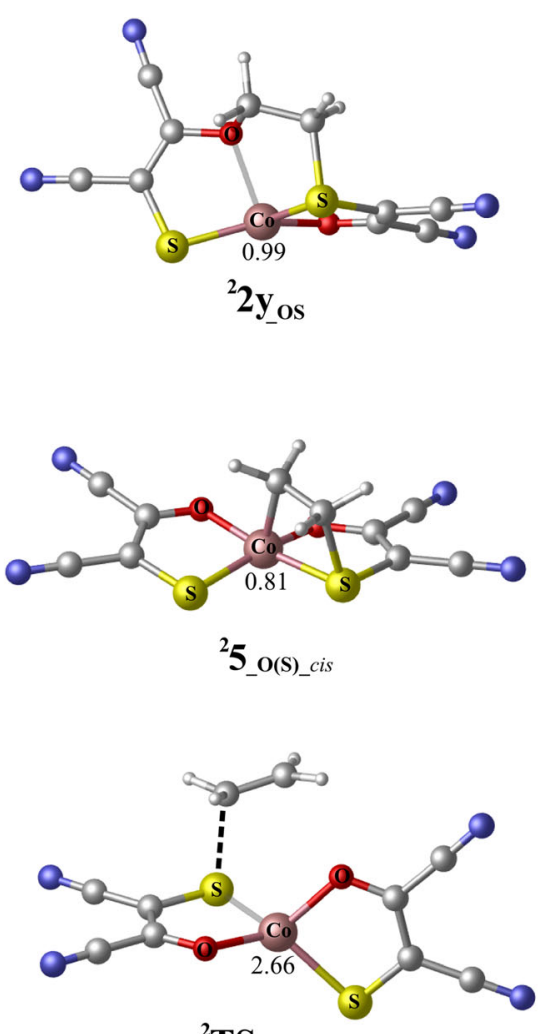

${ }^{2} \mathbf{T S}_{2 \mathbf{y}_{-} \mathbf{O}(\mathbf{S}) \mathbf{A}}$
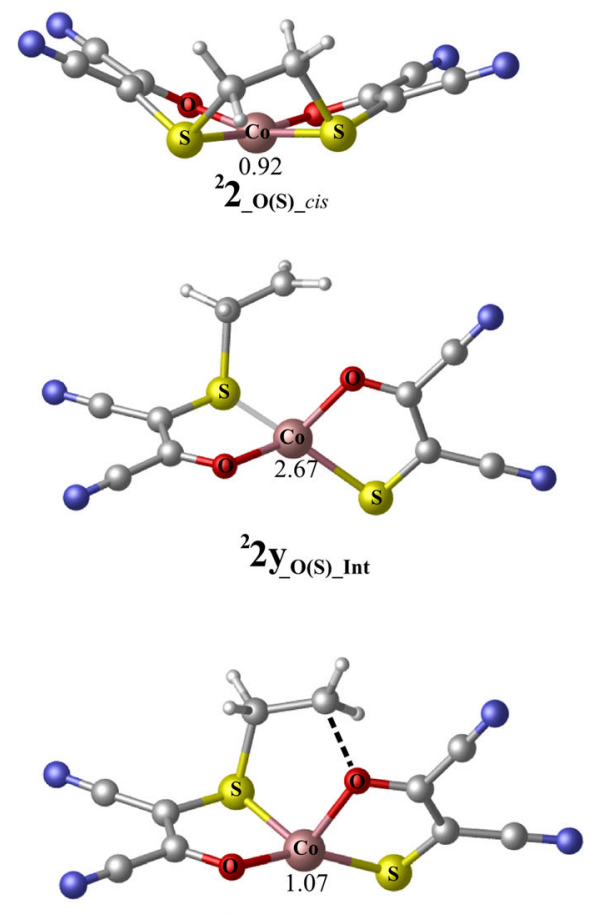

${ }^{2} \mathbf{T S}_{2 \mathbf{y}} \mathbf{O}(\mathbf{S})$ в

Fig. 4 The optimized geometries for the selected species of $c i s$-isomer that are included in Fig. 3. Values correspond to atomic spin densities. The geometries of selected species for trans-isomer are presented in Electronic Supplementary Material (Fig. S6) 
biradical electron distribution). This intermediate is formed with a barrier of $10.0 \mathrm{kcal} / \mathrm{mol}\left({ }^{\mathbf{2}} \mathbf{T S}_{\mathbf{2}_{\mathbf{y}} \mathbf{O} \mathbf{O}(\mathbf{S}) \_\mathbf{A}}\right)$ but needs to overcome the large additional barrier (formation of $\mathrm{C}-\mathrm{O}$ bond) of $20.2 \mathrm{kcal} / \mathrm{mol}$ to further generate ${ }^{2} \mathbf{2 y}$ _so

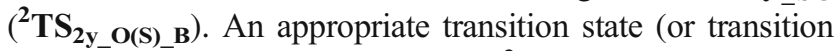
states) forming an intraligand adduct ${ }^{\mathbf{2}} \mathbf{3}_{\text {_os_cis }}$ in a direct pathway was not obtained, and this reaction is discarded. Regarding the indirect pathway, the intermediate ${ }^{\mathbf{2}} \mathbf{5}$ o(S)_cis (only $0.4 \mathrm{kcal} / \mathrm{mol}$ relative to separate ${ }^{\mathbf{2}} \mathbf{1}_{-} \mathrm{Co}_{-} \mathrm{O}$ s_cis $_{-}$and ethylene), can be formed through the transition state ${ }^{\overline{2}} \mathbf{T S}_{\mathbf{1 5} \_\mathbf{O}(\mathbf{S}) \_ \text {cis }}$ with a barrier of $9.8 \mathrm{kcal} / \mathrm{mol}$ (Fig. 3). 5_o(S)_cis can isomerize into three different products: interligand adduct ${ }^{2} \mathbf{2}$ o(S)_cis via ${ }^{2} \mathbf{T S}_{52 \_} \mathbf{O}(\mathbf{S}) \_c i s$, interligand adduct ${ }^{2} \mathbf{2} \mathbf{y}_{-}$so via ${ }^{\mathbf{2}} \mathbf{T S}_{\mathbf{5 2} \mathbf{y}} \mathbf{O} \mathbf{O}(\mathbf{S}) \_c i s$,

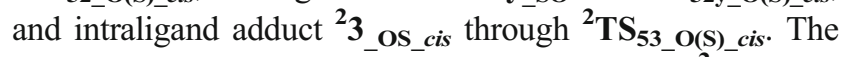
energy favored process is clearly the formation of ${ }^{2} \mathbf{2} \_\mathbf{O}(\mathbf{S}) \_c i s$, with a barrier of $9.8 \mathrm{kcal} / \mathrm{mol} ; 24.3 \mathrm{kcal} / \mathrm{mol}$ more favorable than forming the intraligand adduct and $20.9 \mathrm{kcal} / \mathrm{mol}$ more favorable than forming ${ }^{\mathbf{2}} \mathbf{2} \mathbf{y}_{2}$ so. Generally, the formation of desired interligand adduct ${ }^{\mathbf{2}} \mathbf{2}$ O(S)_cis is both thermodynamically and kinetically driven. In respect to the O-binding side, the most favorable of the described pathways is the indirect pathway, but all the pathways must be considered as a noncompetitive due to the much higher energies (Electronic Supplementary Material; Fig. S5). By comparing the kinetic barriers, the preferred mechanism for the ethylene addition to ${ }^{2}$ __Co_os_cis is the formation of ${ }^{2} \mathbf{2}$ o(S)_cis by the indirect pathway along the S-binding side with a rate determining step of $9.8 \mathrm{kcal} / \mathrm{mol}$. There is a significant kinetic preference for the formation of this product, with a barrier 24.3 more favorable than the formation of intraligand adduct ${ }^{\mathbf{2}} \mathbf{3}$ os_cis. Furthermore, the intraligand adduct ${ }^{\mathbf{2}} \mathbf{3}_{\text {_os_cis }}$ is thermodynamically less stable than interligand adducts ${ }^{2}$ 2_o(s)_cis and ${ }^{2} 2$ y_so by 25.7 and $11.9 \mathrm{kcal} / \mathrm{mol}$, respectively.

Figure 3 also shows the calculated energy profiles for the reaction of ${ }^{2} \mathbf{1}_{\text {Co_os_trans }}$ with ethylene. The direct pathway (dotted lines) was only found on the S-binding side, likewise previously described for the ${ }^{\mathbf{4}_{1}}$ Co_os. The direct pathway is also stepwise and it begins with the formation of intermediate

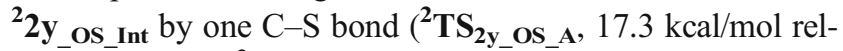
ative to separate ${ }^{2}$ 1_Co_os_trans and ethylene), followed by the formation of a second $\mathrm{C}-\mathrm{S}$ bond producing the tetrahedral product ${ }^{2} \mathbf{2} \mathbf{y}_{-} \mathbf{o}$ (s) with the barrier of $5.4 \mathrm{kcal} / \mathrm{mol}$

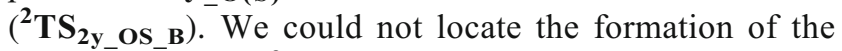
intraligand adduct ${ }^{\mathbf{2}} \mathbf{3}_{\text {_os }}$ trans along the direct pathway. On the indirect pathway (solid lines), intermediate ${ }^{\mathbf{2}} \mathbf{5}$ _o(S)_trans, $0.7 \mathrm{kcal} / \mathrm{mol}$ relative to the separate ${ }^{\mathbf{2}} \mathbf{1}_{\text {_Co_os_trans }}$ and ethylene, can be formed through the activation barrier of $10.6 \mathrm{kcal} /$

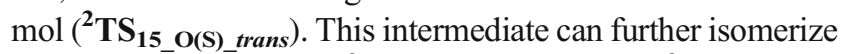
into interligand adducts ( ${ }^{2} \mathbf{2}$ os_trans (planar) and ${ }^{2} \mathbf{2} \mathbf{y} \_\mathbf{o ( s )}$ (tetrahedral)) or into intraligand adduct ${ }^{2} \mathbf{3}$ os_trans. Here, the barriers toward ${ }^{\mathbf{2}} \mathbf{2}$ os_trans $\left({ }^{\mathbf{2}} \mathbf{T S}_{\mathbf{5 2} \_} \mathbf{O}(\mathbf{S}) \_\right.$trans $)$and ${ }^{\mathbf{2}} \mathbf{2} \mathbf{y}_{-} \mathbf{O}(\mathbf{S})$ $\left({ }^{2} \mathbf{T S}_{\left.\mathbf{5 2 y} \mathbf{y}_{\mathbf{C}} \mathbf{O}(\mathbf{S})_{\text {trans }}\right)}\right)^{-}$are 15.8 and $21.3 \mathrm{kcal} / \mathrm{mol}$ lower in energy

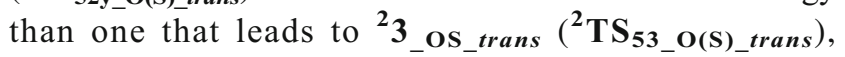

respectively (see Fig. 3). In addition, ${ }^{2} \mathbf{2}$ os trans and ${ }^{\mathbf{2}} \mathbf{2 y}$ o(s) are more stable than ${ }^{2} \mathbf{3}$ os trans by 15.9 and $28.4 \mathrm{kcal} / \mathrm{mol}$, respectively. The O-binding reaction was found through an indirect mechanism, but it has significantly higher energies and can be discarded without detailed discussion (Electronic Supplementary Material; Fig. S5). The energy preferred mechanism for the ethylene addition to ${ }^{\mathbf{2}} \mathbf{1}_{-}$Co_os_trans is the indirect, S-binding route that leads to ${ }^{\mathbf{4}} \mathbf{2} \mathbf{y}_{-} \mathbf{o}(\mathbf{S})$ with a ratedetermining barrier of $16.2 \mathrm{kcal} / \mathrm{mol}$. On the other hand, the rate-determining barrier that leads to the formation of intraligand adduct ${ }^{\mathbf{2}}{ }^{3}$ os_trans is $37.5 \mathrm{kcal} / \mathrm{mol}$. Therefore, this pathway has kinetic selectivity toward the formation of the most stable interligand adduct of $21.3 \mathrm{kcal} / \mathrm{mol}$. By comparing the two pathways, the direct pathway exclusively leads to ${ }^{4} \mathbf{2} \mathbf{y}_{\mathbf{O}} \mathbf{O}(\mathbf{S})$, with a rate-determining barrier $20.2 \mathrm{kcal} / \mathrm{mol}$ lower than the rate-determining barrier forming ${ }^{2} \mathbf{3}$ os_trans through the indirect pathway. From the above, it can be concluded that the reaction between ${ }^{2} \mathbf{1}_{\text {Co_os_trans }}$ and ethylene prefers the formation of interligand adducts with respect to the intraligand adduct, both thermodynamically and kinetically, thereby minimizing the decomposition route.

In summary, all cobalt bis (oxothiolene) complexes (in both spin states) favor the formation of desired interligand adducts over the formation of the respective intraligand adducts, both kinetically and thermodynamically. This complex exceeds the performances of parent 1_Ni_ss complex [21, 22] for olefin purification and display better properties than 1_Co_ss [23]. This can be viewed in terms of enhanced kinetic and thermodynamic selectivity toward the formation of interligand adduct, although the rate-determining barriers are somewhat lower in the case of 1_Co_ss (Electronic Supplementary Material; Fig. S7). The characteristics of 1_Co_os complexes, as a potential catalyst, are quite similar with those for 1_Ni_os complexes [24] that were previously published (Electronic Supplementary Material; Fig. S7). Thus, it can be concluded that oxothiolene complexes show better performances than dithiolene complexes as catalysts for the olefin purification process.

The ethylene-release pathway from the reduced adducts For being usable in electro-catalytic olefin purification, the complexes should release the olefin upon reduction. Considering that ${ }^{\mathbf{3}} \mathbf{2}_{\text {_Co_os }}{ }^{-}$and ${ }^{\mathbf{3}} \mathbf{2} \mathbf{y}_{-} \mathrm{Co}_{-} \mathrm{Os}^{-}$adducts are significantly more stable than their singlet counterparts (Table 1), we only present here the release of ethylene on the triplet state surface (Fig. 5), but an energy profile for the singlet state surface is presented in Electronic Supplementary Material (Fig. S8). The release of ethylene is favorable on both spin states, and even more favorable on the triplet state surface. Only the cis isomer ethylene releasing pathway from anionic adducts is shown, because cis neutral adduct is more stable than trans isomer. Therefore, following the indirect pathway ethylene can be released from ${ }^{3}{ }_{2}$ Oo(S)_cis ${ }^{-}$by overcoming an activation barrier 


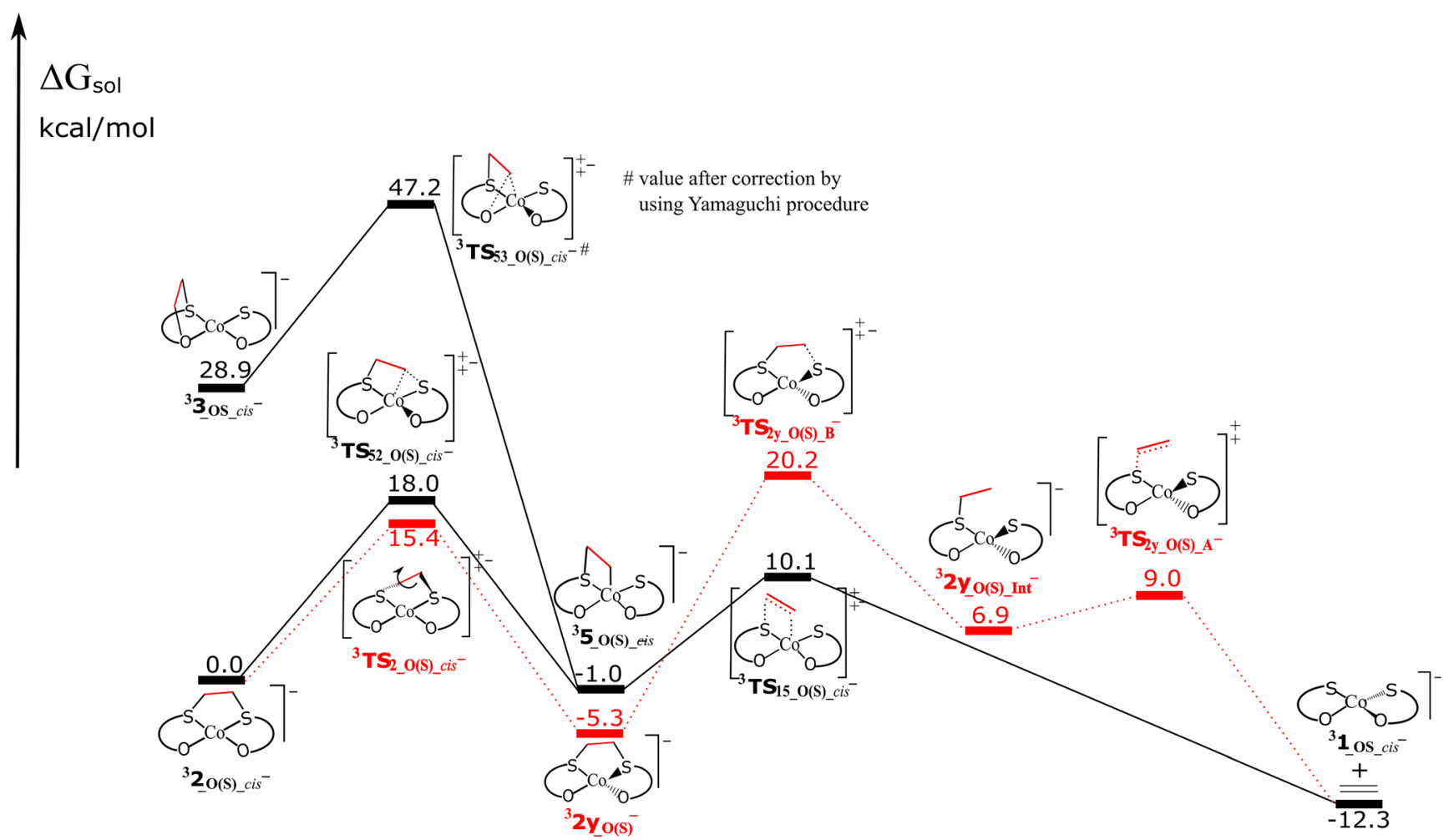

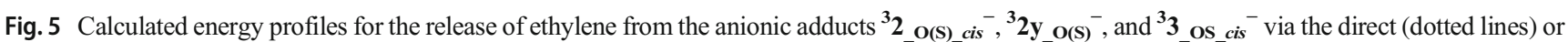
the indirect pathway (solid lines). Energies in $\mathrm{kcal} / \mathrm{mol}$ are the free energy in solvent

of $\left.18.0 \mathrm{kcal} / \mathrm{mol}^{\mathbf{3}^{3}} \mathbf{T S}_{\mathbf{5 2} \_} \mathbf{O}(\mathbf{S}) \_c i{ }^{-}\right)$, which is the ratedetermining barrier for this pathway (Fig. 5). This process is exothermic by $12.3 \mathrm{kcal} / \mathrm{mol}$. Alternatively, ${ }^{\mathbf{3}} \mathbf{2}$ o(S)_cis ${ }^{-}$can isomerize into ${ }^{3} \mathbf{2} \mathbf{y}_{-} \mathbf{O}\left(\mathrm{S}^{-}{ }^{-}\right.$by crossing a $15.4 \mathrm{kcal} / \mathrm{mol}$ barrier, from which ethylene can be released following the direct pathway with a rate-determining barrier of $25.5 \mathrm{kcal} / \mathrm{mol}$ $\left({ }^{3} \mathbf{T S}_{\mathbf{2} \mathbf{Y}} \mathbf{O}(\mathbf{S}) \mathbf{B}_{\mathbf{B}}{ }^{-}\right)$. However, this is a more energy-demanding pathway, with a rate-determining barrier $7.5 \mathrm{kcal} / \mathrm{mol}$ higher than the indirect pathway. In addition, the release of ethylene from intraligand adduct ${ }^{\mathbf{3}}{ }_{-}$os_cis $^{-}$is also possible through a barrier of $\left.18.3 \mathrm{kcal} / \mathrm{mol}^{3}{ }^{3} \mathbf{T S}_{\mathbf{5 3} \_} \mathbf{O}(\mathbf{S}) \_c i{ }^{-}\right)$, although the formation of this adduct is unfavorable. The rate-determining step for the ethylene release on the singlet state surface is $15.9 \mathrm{kcal} /$ mol (corresponding also to the indirect mechanism; Fig. S8). Therefore, ethylene can be easily released from $c i s$-interligand adduct 2 o(s) cis $^{-}$, on both states, following the indirect pathways, which are kinetically favored.

Reaction mechanisms of copper bis (oxothiolene) complexes with ethylene According to the thermodynamic data in Table 1, copper complexes (both neutral and cationic) might be alternative catalysts only if the intraligand adducts do not decompose. For the neutral complex in lower spin state $\left({ }^{2} 1_{\text {Cu_os cis }}\right)$, as well as for the cationic complex in higher spin state $\left({ }^{\mathbf{3}} \mathbf{1}_{\text {Cu_os }}{ }_{\text {cis }}{ }^{+}\right)$, the formation of intraligand adduct 3 is slightly thermodynamically favored comparing to the formation of cis-interligand adduct $\mathbf{2}$, whereas for the cationic complex in lower spin state $\left({ }^{1} \mathbf{1}_{-} \mathbf{C u} \_\right.$os $\left.{ }^{+}\right)$, the formation of adduct 3 is highly favored (Table 1). However, adducts

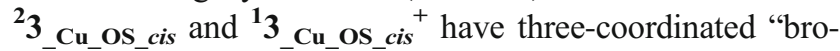
ken" geometries that suggest that the decomposition process is accessible, whereas ${ }^{{ }^{3}}{ }_{\text {_Cu_os_cis }}{ }^{+}$species represents the usual intraligand adduct (without breaking any metal-ligand bond). Even though ${ }^{\mathbf{3}_{3}} \mathrm{Cu}$ os ${ }_{\text {cis }}{ }^{+}$does not favor the decomposition, it is $7.5 \mathrm{kcal} / \mathrm{mol}$ less stable than ${ }^{\mathbf{1}} \mathbf{3}_{\text {Cu }}$ Os cis ${ }^{+}$which does (Table 1). Therefore, neutral and cationic copper bis (oxothiolene) complexes can be excluded as alternative catalysts because of catalyst decomposition.

On the other hand, the anionic copper complex ${ }^{1} 1_{\text {Cu os cis }}{ }^{-}$might be a better alternative catalyst, because the reaction that leads to the formation of cis-interligand adducts 2 and $\mathbf{2 y}$ are exothermic $(-13.4$ and $-17.4 \mathrm{kcal} / \mathrm{mol}$, respectively) and the reaction to form the intraligand adduct 3 is predicted to be close to zero free energy change. The complex in triplet state $\left({ }^{3} 1_{\mathbf{C u}_{-} \text {os }^{-}}\right)$, though more stable by $0.8 \mathrm{kcal} / \mathrm{mol}$ than the complex in singlet state $\left({ }^{1} 1_{\text {Cu_os }}\right.$ cis $\left.{ }^{-}\right)$, exhibits unfavorable thermodynamics for the formation of all three adducts with ethylene (Table 1). Therefore, only the singlet-state energy surface for this complex was explored by locating all transition states (Fig. 6). Following the direct pathway, the twisted intermediate ${ }^{1} \mathbf{2} \mathbf{y}_{\mathbf{C u}}$ os $^{-}$(tetrahedral) is generated with an activation barrier of $28.2 \mathrm{kcal} / \mathrm{mol}\left({ }^{1} \mathbf{T S}_{\mathbf{2 y}} \mathbf{C u}_{-} \mathbf{O}{ }_{-}\right.$cis $\left.{ }^{-}\right)$. This product can further isomerize into ${ }^{1}$ __Cu_Os_cis ${ }^{2}$ (planar) through transition state 


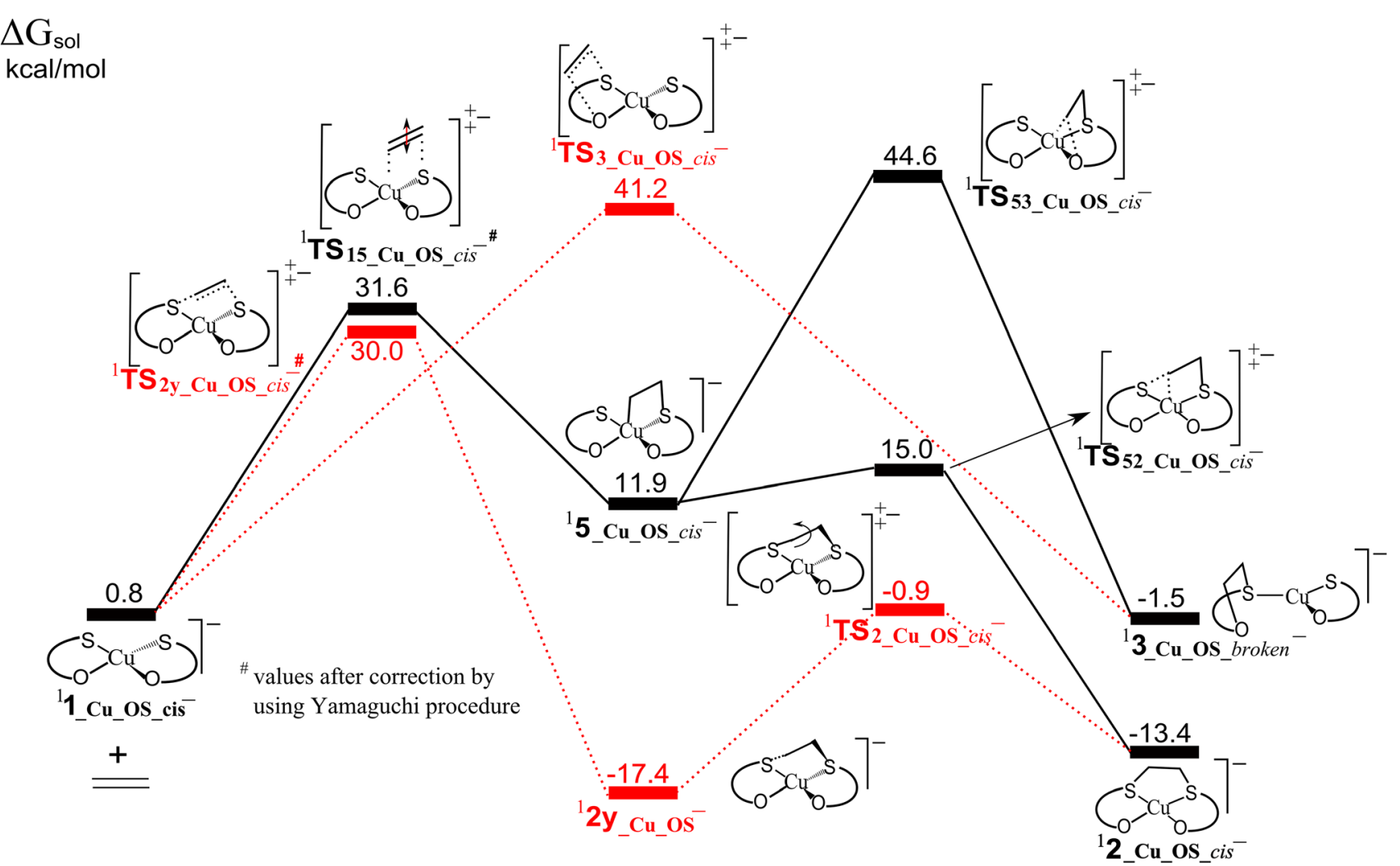

Fig. 6 Calculated energy surfaces for the reaction of ${ }^{\mathbf{1}} \mathbf{1}_{-} \mathbf{C u} \_\mathbf{O} \_$cis ${ }^{-}$with ethylene. Dotted (red) and solid (black) lines represent direct and indirect pathway, respectively. Energies in $\mathrm{kcal} / \mathrm{mol}$ are the free energy in solvent

${ }^{1} \mathbf{T S}_{\mathbf{2}}{ }_{\mathbf{C u}} \mathbf{O S}_{-}$cis ${ }^{-}$, by additionally passing the barrier of $16.5 \mathrm{kcal} / \mathrm{mol}$. However, the second step is endothermic by $4.0 \mathrm{kcal} / \mathrm{mol}$, indicating that the twisted, tetrahedral intermediate is the final product for this reaction. Alternatively, the intraligand adduct ${ }^{1}{ }_{3}$ Cu_broken ${ }^{-}$can be formed directly with a higher barrier of $40.4 \mathrm{kcal} / \mathrm{mol}\left({ }^{\mathbf{1}} \mathbf{T S}_{\mathbf{3}_{-} \mathbf{C} \mathbf{C}_{-} \mathbf{O} \mathbf{S}_{-} \text {cis }}{ }^{-}\right)$. The indirect pathway begins with transition state ${ }^{-1} \mathbf{T S}_{15}{ }_{1} \mathbf{C u}_{-}$os_cis ${ }^{-}$imposing the energy barrier of $30.8 \mathrm{kcal} / \mathrm{mol}$, which lead to the formation of intermediate ${ }^{\mathbf{1}} \mathbf{5}_{\text {Cu_os_cis }}{ }^{-}$. This intermediate is $11.1 \mathrm{kcal} / \mathrm{mol}$ relative to the separate ${ }^{\mathbf{1}} \mathbf{1}_{-} \mathbf{C u}_{-}$os_cis ${ }^{-}$and ethylene and can subsequently isomerize into both interligand ${ }^{1}{ }_{C}$ Cu_Os_cis ${ }^{-}$or intraligand ${ }^{\mathbf{1}} \mathbf{3}_{\text {Cu_broken }}{ }^{-}$adducts, by overcoming the barriers of $3.1 \mathrm{kcal} / \mathrm{mol}\left({ }^{\mathbf{1}} \mathbf{T S}_{\mathbf{5 2}} \mathbf{C u}_{-} \mathbf{O} \mathbf{O S}_{-} c i{ }^{-}\right)$and

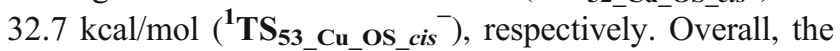
reaction of ${ }^{1} 1_{1}$ Cu_os_cis with ethylene favors the formation of the interligand adducts ( ${ }^{\mathbf{1}} \mathbf{2} \mathbf{y}_{-} \mathbf{C u}{ }_{-}{ }^{-}{ }^{-}$and ${ }^{1} \mathbf{2}_{\text {_Cu_os_cis }}$ ) both kinetically and thermodynamically. Although the interligand adducts are enough thermodynamically stable, the barriers for their formation are somewhat higher that can be attributed to the fact that ethylene, which act as a nucleophile, approaches to the negative species. Therefore, ${ }^{\mathbf{1}} \mathbf{1}_{\text {Cu_os_cis }}{ }^{-}$cannot be considered as a good candidate for olefin separation process, but it shows somewhat better properties comparing to the previously published ${ }^{\mathbf{1}} \mathbf{1}_{-} \mathbf{C u} \mathbf{C u}_{\mathbf{S}}{ }^{-}$complex [23]. Further modifications of ligands might lead to the copper complexes with enhanced catalytic properties. The relative stabilities of ${ }^{2} 2$ Cu_os_cis ${ }^{2-}$ and ${ }^{2} \mathbf{2} y_{-}$Cu_os_cis ${ }^{2-}$ species indicate that the release of ethylene from adducts ${ }^{1} \mathbf{2}_{-} \mathbf{C u}_{-} \mathbf{O s}_{-}$cis ${ }^{-}$and $\mathbf{1}_{\mathbf{2}} \mathbf{y}_{\mathbf{C}} \mathbf{C u}_{-} \mathbf{O s}_{-}$cis ${ }^{-}$is thermodynamically favored (Table 1).

\section{Conclusion}

In summary, we performed DFT calculations to predict a suitable catalyst for olefin purification. Inspired by our previous results, the differently charged cobalt and copper bis (oxothiolene) complexes of general formula [M $\left.\left(\mathrm{OSC}_{2}(\mathrm{CN})_{2}\right)_{2}\right]^{n}(\mathrm{M}=\mathrm{Co}, n=-1,0 ; \mathrm{M}=\mathrm{Cu}, n=+1,0,-1$, -2 ) have been examined by exploring their reactivity with ethylene. For each complex, both the lower spin state (singlet or doublet) and the first higher spin state were considered to predict the thermodynamic stability of the cis-interligand and intraligand products. For those complexes with favorable thermodynamics (it is $\left[\mathrm{Co}\left(\mathrm{OSC}_{2}(\mathrm{CN})_{2}\right)_{2}\right]$ and $[\mathrm{Cu}$ $\left.\left.\left(\mathrm{OSC}_{2}(\mathrm{CN})_{2}\right)_{2}\right]^{-}\right)$, further mechanistic calculations were performed to explore kinetic feasibility of different pathways.

The results suggest that the neutral cobalt complex 1_Co_os might be an alternative catalyst that performs 
better than the original 1_Ni_ss. This is because 1_Co_os preferably forms interligand adducts over the intraligand adducts, which are both kinetically and thermodynamically driven, thereby avoiding the decomposition issues of the nickel system. This happens with all the considered isomers and spin states, which includes two square-planar doublet species, cis and trans, and one tetrahedral complex in quartet state. In all cases, the direct pathways are stepwise and exclusively lead to the formation of interligand adducts. The indirect pathways also prefer formation of interligand adducts with relatively low-lying transition states, but intraligand products can be also formed with higher barriers. Consequently, $1_{\text {Co }}$ os complexes have no need for anionic species as a co-catalyst to produce desired interligand adduct, which are crucial for the original nickel complex. In addition, it was shown that upon reduction, the interligand adducts $\left({ }^{1 / 3} \mathbf{2} \_\mathbf{O}(\mathbf{S}){ }_{-} c i{ }^{-}\right.$and ${ }^{\mathbf{1}}$ ${ }^{3} \mathbf{2} \mathbf{y}_{\mathbf{O}}\left(\mathrm{Ss}^{-}\right)$can easily release ethylene, following the indirect pathway, to produce ${ }^{\mathbf{1} / \mathbf{3}} \mathbf{1}_{-} \mathrm{Co}_{\mathbf{C}} \mathbf{\text { os }}{ }^{-}$and regenerate the catalyst. It turns out that these complexes also perform better than analogous 1_Co_ss complex, by farther favoring the formation of the interligand adduct. According to the required performances for this type of catalysis, it appears that 1_Co_os is comparable to the 1_Ni_os complexes, thereby categorizing oxothiolene complexes as better candidates than the dithiolene complexes.

In the case of copper complexes, the neutral and cationic species are not good candidates for the catalyst due to the high relative thermodynamic stability of intraligand adducts, which have three-coordinated geometries (broken) that strongly indicate further decomposition. The mono-anionic complex 1_Cu_os_cis ${ }^{-}$might be considered as a potential catalyst, whose performances are somewhat better comparing to the analogous 1_Cu_ss ${ }^{-}$complex that was previously published. However, activation barriers for both direct and indirect pathways are somewhat higher and amount 30.0 and $31.6 \mathrm{kcal} /$ mol, respectively. Therefore, further modifications of the ligand are required for obtaining the catalyst featured by lower activation barriers. Anyhow, all these results can give directive to the design of a series of novel complexes whose applicability can be validated experimentally.

Acknowledgments The calculations were performed at the RAAD2 supercomputer at the Texas A\&M University at Qatar.

Funding information Open Access funding provided by the Qatar National Library. This publication was made possible by the Qatar National Research Fund through the NPRP grants 8-028-1-001 and 5-318-1-063.

\section{Compliance with ethical standards}

Ethical statement The authors do not have any financial relationship with the sponsor of this work beyond the grants received to perform such work.
Open Access This article is licensed under a Creative Commons Attribution 4.0 International License, which permits use, sharing, adaptation, distribution and reproduction in any medium or format, as long as you give appropriate credit to the original author(s) and the source, provide a link to the Creative Commons licence, and indicate if changes were made. The images or other third party material in this article are included in the article's Creative Commons licence, unless indicated otherwise in a credit line to the material. If material is not included in the article's Creative Commons licence and your intended use is not permitted by statutory regulation or exceeds the permitted use, you will need to obtain permission directly from the copyright holder. To view a copy of this licence, visit http://creativecommons.org/licenses/by/4.0/.

\section{References}

1. Eldridge RB (1993) Olefin/paraffin separation technology: a review. Ind Eng Chem Res 32:2208-2212. https://doi.org/10.1021/ ie00022a002

2. Blytas GC (1992) Separation of unsaturates by complexing with nonaqueous solutions of cuprous salts. In: Li NN, Calo JM (eds) Separation and purification technology. Dekker, New York, pp 19-58

3. Grantom RL, Royer DJ (1987) Ullmann's Encyclopedia of Industrial Chemistry, vol 45. 5th edn. VCH, New York

4. Suzuki T, Noble RD, Koval CA (1997) Electrochemistry, stability, and alkene complexation chemistry of copper(I) triflate in aqueous solution. Potential for use in electrochemically modulated complexation-based separation processes. Inorg Chem 36:136-140

5. Wang K, Stiefel EI (2001) Toward separation and purification of olefins using dithiolene complexes: an electrochemical approach. Science 291:106-109. https://doi.org/10.1126/science.291.5501.106

6. Wing RM, Tustin GW, Okamura WH (1970) Oxidative cycloaddition of metal dithiolenes to olefins. Synthesis and characterization of norbornadiene-bis-cis-(1,2-perfluoromethylethene-1,2dithiolato) nickel. J Am Chem Soc 92:1935-1939

7. Harrison DJ, Nguyen N, Lough AJ, Fekl U (2006) New insight into reactions of $\mathrm{Ni}\left(\mathrm{S}_{2} \mathrm{C}_{2}\left(\mathrm{CF}_{3}\right)_{2}\right)_{2}$ with simple alkenes: alkene adduct versus dihydrodithiin product selectivity is controlled by $\left[\mathrm{Ni}\left(\mathrm{S}_{2} \mathrm{C}_{2}\left(\mathrm{CF}_{3}\right)_{2}\right)_{2}\right]-$ anion. J Am Chem Soc 128:11026-11027

8. Clark GR, Waters JM, Whittle KR (1973) Crystal structure of the 1: 1 adduct formed between bis (cis-1,2-diphenylethylene-1,2dithiolato) palladium and cyclohexa-1,3-diene. J Chem Soc Dalton Trans 821-824

9. Kajitani M, Kohara M, Kitayama T, Asano Y, Sugimori A (1986) Photosensitive 1:1 adduct between Bis(1,2-diphenyl-1,2ethylenedithiolato)nickel(0) and quadricyclane. Chem Lett 15: 2109-2112

10. Kajitani M, Kohara M, Kitayama T, Akiyama T, Sugimori A (1989) Formation of 1:1 adducts between bis(1,2-diaryl-1,2ethylenedithiolato $) \operatorname{metal}(0)($ metal $=\mathrm{Ni}, \mathrm{Pd}$, and $\mathrm{Pt})$ and quadricyclane and their photodissociation. J Phys Org Chem 2: 131-145

11. Kunkely H, Vogler A (2001) Excited state properties of norbornadiene adducts of nickel (II), palladium (II) and platinum (II) bis-1,2-diphenyl-1,2-dithiolene complexes. Inorg Chim Acta 319:183-186

12. Geiger WE (2002) Electrochemistry of cycloaddition products of olefins with nickel dithiolenes: a reinvestigation of the reduction of the $1: 1$ adduct between $\mathrm{Ni}\left(\mathrm{S}_{2} \mathrm{C}_{2}\left(\mathrm{CF}_{3}\right)_{2}\right)_{2}$ and norbornadiene. Inorg Chem 41:136-139

13. Schrauzer GN, Mayweg VP (1965) Preparation, reactions, and structure of bisdithio- $\alpha$-diketone complexes of nickel, palladium, and platinum. J Am Chem Soc 87:1483-1489 
14. Schrauzer GN, Rabinowitz HN (1968) Charge distribution and nucleophilic reactivity in sulfur ligand chelates. Dialkyl derivatives of nickel (II), palladium (II), and platinum (II) bis (cis ethylenedithiolates). J Am Chem Soc 90:4297-4302

15. Schrauzer GN, Ho RKY, Murillo RP (1970) Structure, alkylation, and macrocyclic derivatives of bicyclo[2.2.1]hepta-2,5-diene adducts of metal dithienes. J Am Chem Soc 92:3508-3509

16. Zhang CH, Reddy K, Chadha RK, Schrauzer GN (1992) Synthesis, structures and dynamic properties of trimethylene- and tetramethylene-Bis (CIS-stilbene-1,2-dithiolato) nickel (II). J Coord Chem 26:117-126

17. Schmitt RD, Wing RM, Maki AH (1969) Donor-acceptor complexes of the inorganic .pi. acceptor, bis-cis-(1,2perfluoromethylethene-1,2-dithiolato)nickel. J Am Chem Soc 91: 4394-4401

18. Baker JR, Hermann A, Wing RM (1971) Mechanism of oxidative cycloaddition of olefins to metal dithiolenes. J Am Chem Soc 93: 6486-6489

19. Herman A, Wing RM (1973) The structure of the nickel bis(1,2ethenedithiolate)/2,3-dimethylbutadiene cycloaddition reaction product. J Organomet Chem 63:441-450

20. Fan Y, Hall MB (2002) How electron flow controls the thermochemistry of the addition of olefins to nickel dithiolenes: predictions by density functional theory. J Am Chem Soc 124:1207612077

21. Dang L, Shibl MF, Yang X, Alak A, Harrison DJ, Fekl U, Brother EN, Hall MB (2012) The mechanism of alkene addition to a nickel bis (dithiolene) complex: the role of the reduced metal complex. J Am Chem Soc 134:4481-4484

22. Dang L, Shibl MF, Yang X, Harrison DJ, Alak A, Lough AJ, Fek1 U, Brother EN, Hall MB (2013) Apparent anti-WoodwardHoffmann addition to a nickel bis (dithiolene) complex: the reaction mechanism involves reduced, dimetallic intermediates. Inorg Chem $52: 3711$

23. Li H, Brothers EN, Hall MB (2014) Computational exploration of alternative catalysts for olefin purification: cobalt and copper analogues inspired by nickel Bis (dithiolene) electrocatalysis. Inorg Chem 53:9679-9691

24. Sredojevic DN, Raju RK, Moncho S, Brothers EN (2016) Mechanism of ethylene addition to nickel bis (oxothiolene) and nickel bis (dioxolene) complexes. J Phys Chem A 120:7561-7568

25. Raju RK, Sredojevic DN, Moncho S, Brothers EN (2016) Nickel bis (diselenolene) as a catalyst for olefin purification. Inorg Chem 55:10182-10191

26. Dang L, Ni SF, Hall MB, Brothers EN (2014) Uptake of one and two molecules of 1,3-butadiene by platinum bis (dithiolene): a theoretical study. Inorg Chem 53:9692-9702

27. Moncho S, Brothers EN, Hall MB (2015) Addition of ethylene to a $\pi$-conjugated two-dimensional nickel-based organometallic framework with implications for olefin separation. J Mol Model 21:107

28. Sredojevic DN, Moncho S, Raju RK, Belic MR, Brothers EN (2018) Reversible olefin addition to extended lattices of a nickel -selenium framework. J Phys Chem C 122:22424-22434
29. Frisch MJ, Trucks GW, Schlegel HB, Scuseria GE, Robb MA, Cheeseman JR, Scalmani G, Barone V, Mennucci B, Petersson GA, Nakatsuji H, Caricato M, Li X, Hratchian HP, Izmaylov AF, Bloino J, Zheng G, Sonnenberg JL, Hada M, Ehara M, Toyota K, Fukuda R, Hasegawa J, Ishida M, Nakajima T, Honda Y, Kitao O, Nakai H, Vreven T, Montgomery Jr JA, Peralta JE, Ogliaro F, Bearpark M, Heyd JJ, Brothers E, Kudin KN, Staroverov VN, Kobayashi R, Normand J, Raghavachari K, Rendell A, Burant JC, Iyengar SS, Tomasi J, Cossi M, Rega N, Millam JM, Klene M, Knox JE, Cross JB, Bakken V, Adamo C, Jaramillo J, Gomperts R, Stratmann RE, Yazyev O, Austin AJ, Cammi R, Pomelli C, Ochterski JW, Martin RL, Morokuma K, Zakrzewski VG, Voth GA, Salvador P, Dannenberg JJ, Dapprich S, Daniels AD, Farkas Ö, Foresman JB, Ortiz JV, Cioslowski J, Fox DJ (2009) Gaussian development version, revision H.32. Gaussian, Inc, Wallingford

30. Chai JD, Head-Gordon M (2008) Long-range corrected hybrid density functionals with damped atom-atom dispersion corrections. Phys Chem Chem Phys 10:6615-6620

31. Dang L, Yang X, Zhou J, Brother EN, Hall MB (2012) Computational studies on ethylene addition to nickel bis (dithiolene). J Phys Chem A 116:476-482

32. Krishnan R, Binkley JS, Seeger R, Pople JA (1980) Self-consistent molecular orbital methods. XX. A basis set for correlated wave functions. J Chem Phys 72:650-654

33. Fukui K (1981) The path of chemical reactions - the IRC approach. Acc Chem Res 14:363-368

34. Seeger R, Pople JA (1977) Self-consistent molecular orbital methods. XVIII. Constraints and stability in Hartree-Fock theory. J Chem Phys 66:3045-3050

35. Bauernschmitt R, Ahlrichs R (1996) Stability analysis for solutions of the closed shell Kohn-Sham equation. J Chem Phys 104:90479052

36. Yamaguchi K, Jensen F, Dorigo A, Houk KN (1988) A spin correction procedure for unrestricted Hartree-Fock and Møller-Plesset wavefunctions for singlet diradicals and polyradicals. Chem Phys Lett 149:537-542

37. Soda T, Kitagawa Y, Onishi T, Takano Y, Shigeta Y, Nagao H, Yoshioka Y, Yamaguchi K (2000) Ab initio computations of effective exchange integrals for $\mathrm{H}-\mathrm{H}, \mathrm{H}-\mathrm{He}-\mathrm{H}$ and $\mathrm{Mn}_{2} \mathrm{O}_{2}$ complex: comparison of broken-symmetry approaches. Chem Phys Lett 319: 223-230

38. Marenich AV, Cramer CJ, Truhlar DG (2009) Universal solvation model based on solute electron density and on a continuum model of the solvent defined by the bulk dielectric constant and atomic surface tensions. J Phys Chem B 113:6378-6396

39. Legault CY (2009) CYLview, 1.0b, Université de Sherbrooke. http://www.cylview.org

40. Shibl MF, Dang L, Raju RK, Hall MB, Brother EN (2012) A mechanism for the addition of ethylene to nickel bis-dithiolene. Int J Quantum Chem 113:1621-1625

Publisher's note Springer Nature remains neutral with regard to jurisdictional claims in published maps and institutional affiliations. 